\title{
Ethylene-Mediated Modulation of Bud Phenology, Cold Hardiness, and Hormone Biosynthesis in Peach (Prunus persica)
}

\author{
Jianyang Liu ${ }^{1}$, Md Tabibul Islam ${ }^{1}$, Sangeeta Sapkota ${ }^{1}$, Pratibha Ravindran ${ }^{2}$, Prakash P. Kumar ${ }^{2}{ }^{D}$, \\ Timothy S. Artlip ${ }^{3}$ and Sherif M. Sherif ${ }^{1, *}$
}

1 Alson H. Smith Jr. Agricultural Research and Extension Center, Virginia Tech, School of Plant and Environmental Sciences, Winchester, VA 22602, USA; liujy4@vt.edu (J.L.); tabibul@vt.edu (M.T.I.); sangee7@vt.edu (S.S.)

2 Department of Biological Sciences, National University of Singapore, Singapore 117543, Singapore; pratibha@nus.edu.sg (P.R.); prakash.kumar@nus.edu.sg (P.P.K.)

3 Apple Biotechnology, USDA-ARS-Appalachian Fruit Research Station, Kearneysville, WV 25430, USA; tim.artlip@usda.gov

* Correspondence: ssherif@vt.edu; Tel.: +1-540-232-6035

check for updates

Citation: Liu, J.; Islam, M.T.; Sapkota, S.; Ravindran, P.; Kumar, P.P.; Artlip, T.S.; Sherif, S.M. Ethylene-Mediated Modulation of Bud Phenology, Cold Hardiness, and Hormone Biosynthesis in Peach (Prunus persica). Plants 2021, 10, 1266. https:// doi.org/10.3390/plants10071266

Academic Editor: Javier Rodrigo García

Received: 9 May 2021

Accepted: 14 June 2021

Published: 22 June 2021

Publisher's Note: MDPI stays neutral with regard to jurisdictional claims in published maps and institutional affiliations.

Copyright: (c) 2021 by the authors. Licensee MDPI, Basel, Switzerland. This article is an open access article distributed under the terms and conditions of the Creative Commons Attribution (CC BY) license (https:// creativecommons.org/licenses/by/ $4.0 /)$.

\begin{abstract}
Spring frosts exacerbated by global climate change have become a constant threat to temperate fruit production. Delaying the bloom date by plant growth regulators (PGRs) has been proposed as a practical frost avoidance strategy. Ethephon is an ethylene-releasing PGR found to delay bloom in several fruit species, yet its use is often coupled with harmful effects, limiting its applicability in commercial tree fruit production. Little information is available regarding the mechanisms by which ethephon influences blooming and bud dormancy. This study investigated the effects of fall-applied ethephon on bud phenology, cold hardiness, and hormonal balance throughout the bud dormancy cycle in peach. Our findings concluded that ethephon could alter several significant aspects of peach bud physiology, including accelerated leaf fall, extended chilling accumulation period, increased heat requirements, improved cold hardiness, and delayed bloom date. Ethephon effects on these traits were primarily dependent on its concentration and application timing, with a high concentration (500 ppm) and an early application timing (10\% leaf fall) being the most effective. Endogenous ethylene levels were induced significantly in the buds when ethephon was applied at $10 \%$ versus $90 \%$ leaf fall, indicating that leaves are essential for ethephon uptake. The hormonal analysis of buds at regular intervals of chilling hours $(\mathrm{CH})$ and growing degree hours (GDH) also indicated that ethephon might exert its effects through an abscisic acid (ABA)-independent way in dormant buds. Instead, our data signifies the role of jasmonic acid (JA) in mediating budburst and bloom in peach, which also appears to be influenced by ethephon treatment. Overall, this research presents a new perspective in interpreting horticultural traits in the light of biochemical and molecular data and sheds light on the potential role of JA in bud dormancy, which deserves further attention in future studies that aim at mitigating spring frosts.
\end{abstract}

Keywords: peach (Prunus persica); bud dormancy; ethylene; spring frost; plant hormones

\section{Introduction}

Temperate fruit production is often challenged by late spring frosts; the sporadic freezing temperatures that occur during spring after the weather begins to warm up. Spring frosts can damage or kill newly developed flowers and fruitlets, thereby substantially reducing fruit yield and quality. The concerns of spring frosts have been rising in recent years, especially in the context of climate change and its effects on the phenology of woody species and the frequency of freezing events during springtime [1-3]. Spring frosts impact a wide range of temperate perennials and threaten the production of several economically important fruit species such as stone fruits. Stone fruits belong to the genus Prunus in the Rosaceae family, and include among its members peaches, sweet cherries (P.avium), and 
almonds ( $P$. dulcis). In temperate regions, the flowering time of stone fruits often coincides with the occurrence of spring frosts, making floral organs especially prone to frost injuries.

The current approaches in frost management can be active or passive [4]. Active approaches alter the microclimate of the orchards by using devices such as wind machines, surface irrigation, heaters, etc. These techniques produce immediate and direct effects, but are generally cost-ineffective, relatively unreliable, and environmentally unsustainable. Passive methods, on the other hand, are mostly preventive and preemptive. These include cultivation of cold-hardy or late-bloom cultivars, proper selection of planting site, and application of plant growth regulators (PGR) to enhance the freezing tolerance $[5,6]$ or delay flowering date to avoid potential freezes $[7,8]$. The use of PGRs, e.g., ethephon, is gaining more popularity owing to its ease of use and cost-effectiveness.

Ethephon (2-chloroethylphosphonic acid) is an ethylene-based PGR that has demonstrated effectiveness in protecting fruit trees against spring frosts. Ethephon decomposes to ethylene after entering plant cells, and its effects are generally attributed to ethylene [9]. Many studies have documented that fall applications of ethephon can delay bloom in many fruit species, especially stone fruits. In peach, for instance, ethephon can delay bloom for up to 18 days post the natural bloom date [10], which may greatly reduce the odds of frost damage. However, the efficacy of ethephon largely depends on concentrations and application timing. Application timing is specifically critical, as harmful effects on flower buds were observed when the application was made after endodormancy [11], and effects on bloom time became insignificant when ethephon was applied during endodormancy [7]. In addition to delaying bloom, ethephon was also found to enhance flower bud hardiness in late winter by delaying deacclimation [11]. However, the practical benefits of ethephon are largely offset by its harmful effects, which include gummosis, leaf yellowing and abscission, terminal dieback, flower abscission, floral bud failure, and reduced fruit yield [12-14]. These detrimental effects have posed a great limitation in using ethephon for bloom delay in commercial production settings. Exploring chemical alternatives to induce bloom delay without risking tree health and yield would require a better understanding of the mechanisms by which ethephon influences flowering, which is largely lacking.

To survive the freezing temperatures in wintertime, the buds of deciduous perennial species enter a phase of dormancy that is characterized by the lack of visible growth or primordia activity. Based on the source of repression signals, winter dormancy can be divided into two sequential phases: endodormancy and ecodormancy. In endodormancy, the growth of terminal and lateral buds is repressed by intrinsic factors, and buds become unresponsive to favorable growth conditions; whereas, in ecodormancy, growth is solely inhibited by unfavorable environmental conditions [15]. During endodormancy, temperate plants require a certain number of chill hours, known as chilling requirement (CR) before the buds can overcome endodormancy and transition to ecodormancy. After endodormancy completion, a period of warm temperatures is required to satisfy heat requirement (HR) for proper bud break and bloom. Both chilling and heat requirements are genetically controlled and are highly species- and cultivar-specific [16]. Commonly, CR is quantified by using temperature-based models, such as the chilling hour $(\mathrm{CH})$ model [17], Utah model [18], and dynamic model [8]. The $\mathrm{CH}$ model assumes that only temperatures between 0 and $7.2^{\circ} \mathrm{C}$ are effective in satisfying CR, and each hour within this temperature range registers as one chilling hour. The Utah model and dynamic model take into consideration the effects of warm weather on accumulated chill, and are suitable for regions where warm spells during dormancy are a concern. The dynamic model assumes a two-step biochemical mechanism for endodormancy release and calculates chilling accumulation as chilling portion (CP) [19]. Heat requirement is commonly estimated as the growing degree hours $(\mathrm{GDH})$ that accumulate from the release of endodormancy to the flowering date (when $50 \%$ of flowers are open, $\mathrm{F}_{50}$ ) [20].

The phenology of dormancy and blooming is tightly controlled by a complex orchestration of several mechanisms, in which phytohormones play a crucial role [21,22]. In this study, we hypothesized that ethephon may alter blooming of peach by modulating the 
metabolisms of phytohormones during dormancy. Specifically, in the present study, we aimed to (1) comprehensively evaluate the overall effects of ethephon on the physiology of peach cultivars during dormancy-flowering stage, with an emphasis on chilling and heat requirements, and blooming; (2) elucidate the dynamics of major phytohormones during dormancy and as affected by ethephon applications; and (3) examine the transcriptional regulation of phytohormones by analyzing the expression of genes responsible for their metabolisms. In this study, we used two peach cultivars to address these research objectives, with an attempt to tap into the potential of using ethephon as a frost mitigation tool, while keeping its negative impacts at tolerable levels.

\section{Materials and Methods}

\subsection{Location and Plant Materials}

This study was conducted at the Alson H. Smith JR Agricultural Research and Extension Center (AREC), Winchester, VA, the United States $(39.11,-78.28)$. This area features a humid subtropical type of climate (Köppen climate classification Cfa), with average temperatures at the peak of hot and cold seasons being $30{ }^{\circ} \mathrm{C}$ and $-3.3^{\circ} \mathrm{C}$ in July and January, respectively. The two peach cultivars used in this study were 'Redhaven' and 'Sunhigh', which were planted in 2012 and 2015, respectively, and both grafted to 'Lovell' rootstock. In this study, we used 'Redhaven' as the primary plant material for the assessment of ethephon effects on leaf abscission, cold hardiness, and hormonal levels, as this cultivar is widely planted and highly prized worldwide.

\subsection{Experimental Design and Treatments}

Two field trials were conducted in fall of 2019 to examine the effects of different concentrations and application times of ethephon on peach. The concentration effects of ethephon were tested on 'Redhaven' using a randomized complete block design (RCBD), in which each of the three rows was treated as a block. In each block, three ethephon concentrations of 100, 300, and $500 \mathrm{ppm}$ (referred to as ET-100, -300 , and $-500 \mathrm{ppm}$ thereafter) plus a control were randomly assigned to four groups, each with two adjacent trees; ethephon was applied on 24 October 2019, corresponding to 50\% of leaf fall (LF). In the 'Sunhigh' orchard, complete randomization design (CRD) was used to examine the effects of application timing. Of the four randomly selected groups, each having three adjacent trees, one was designated as untreated control and the other three were treated with $500 \mathrm{ppm}$ ethephon on 1 October 2019 and 9 November 2019, which correspond to 10, 50, and 100\% LF stages, respectively. In both experiments, at least two buffer trees were included between different treatment trees to reduce the effects of spray drift. Upon application, Motivate (Fine American Inc., Walnut Creek, CA, USA) containing 21\% ethephon was diluted to the desired concentration and mixed with a nonionic surfactant, Regulaid (Kalo Inc., Overland Park, KS, USA), at 250 ppm. For each treatment, an air blast sprayer was used to spray both sides of the trees, and the controls were sprayed with the surfactant only.

\subsection{Chilling and Heat Requirements}

Chilling and heat accumulation were computed from meteorological data obtained from each orchard. Data loggers (EasyLog, Lascar) were kept in enclosed wooden shelters $1.2 \mathrm{~m}$ above the ground and recorded temperatures at $10 \mathrm{~min}$ intervals. Experiments in this study were scheduled based on the accumulation of $\mathrm{CH}$, and the corresponding $\mathrm{CP}$ was also provided. The $\mathrm{CH}$ accumulation was calculated using the $0-7.2^{\circ} \mathrm{C}$ model [17], in which the hourly temperatures within the range of $0-7.2{ }^{\circ} \mathrm{C}$ registered as 1 chilling hour $(\mathrm{CH})$, and temperatures outside of this range were not considered. The $\mathrm{CP}$ was calculated according to Fishman et al. [19]. Starting at $500 \mathrm{CH}$, three one-year old branches, each with at least 15 floral buds, were collected weekly from each treatment. After removal of the terminal buds, the branches were placed in a beaker with the basal ends $3 \mathrm{~cm}$ in a floral solution prepared with Floralife (Smithers-Oasis Co., Walterboro, SC, USA), which was replaced weekly; the basal ends were trimmed back for $1 \mathrm{~cm}$ weekly to avoid 
infections. The branches were kept in a growth chamber with conditions favoring bud growth (photoperiod with fluorescent lamps at $135 \mu \mathrm{mol} \cdot \mathrm{m}^{-2} \cdot \mathrm{s}^{-1}$ of $16 \mathrm{~h}$ at $25^{\circ} \mathrm{C}$, a dark period of $8 \mathrm{~h}$ at $20^{\circ} \mathrm{C}$, and a constant relative humidity of $65 \%$ ). Budbreak was defined when the buds reached the calyx green stage after 14 days in the growth chamber, and CR corresponds to the $\mathrm{CH}$ when budbreak rate reached $50 \%$.

Heat accumulation was computed as growing degree hours (GDH), according to the method proposed by Anderson et al. [9]. In this model, hourly temperatures less than $4.5{ }^{\circ} \mathrm{C}$ registered no $\mathrm{GDH}$; temperatures in the interval of $4.5-25^{\circ} \mathrm{C}$ were adjusted by subtracting $4.5^{\circ} \mathrm{C}$; and temperatures greater than $25^{\circ} \mathrm{C}$ were registered as $20.5(25-4.5){ }^{\circ} \mathrm{C}$. Total GDH was calculated by summing all the GDH from the time when GDH first became detectable to the predetermined ending time. The first GDH in 2020 was recorded on 21 January. Heat requirements (HR) were calculated as the GDH accumulated from the release of endodormancy to the flowering date $\mathrm{F}_{50}$ ( $50 \%$ of opened flowers).

\subsection{Leaf Abscission Assessments}

The effect of ethephon in causing leaf abscission was evaluated in the 'Redhaven' orchard 7 days after ethephon applications. Ten branches were randomly selected per tree and ten leaf nodes starting from the branch tip were recorded as attached or fallen. Leaf abscission rate was calculated as the ratio of number of leafless nodes to the total leaf nodes.

\subsection{Endogenous Ethylene Levels in Leaves and Buds after Ethephon Application}

To evaluate ethephon effects on ethylene induction, we quantified ethylene production rate in buds and leaves of 'Redhaven' at eight time points (1, 2, 3, 6, 9, 15, 21, and 30 days) after treatment with ethephon (500 ppm) at 10 and $90 \%$ leaf fall stages. At each time point, about 15 buds and $25 \mathrm{~g}$ of leaves (fresh weight) were sampled and placed in sealed tubes $(5 \mathrm{~mL})$ and jars $(3750 \mathrm{~mL})$, respectively. Samples were maintained in a growth chamber with a 16:8 h light:dark cycle at $22{ }^{\circ} \mathrm{C}$ for $24 \mathrm{~h}$ before quantification. At analysis, $1 \mathrm{~mL}$ of air from the headspace of each container was withdrawn with a syringe and manually injected into a gas chromatograph (Agilent 7890 A, Agilent Technologies, Wilmington, DE, USA) equipped with a flame ionization detector (FID). The concentration of ethylene (ppm) measured by the gas chromatography was converted to $\mathrm{nmol} \cdot \mathrm{g}^{-1} \cdot \mathrm{h}^{-1}$ by factoring container size, dry weight (DW), and the duration of evolution.

\subsection{Evaluation of Bloom Progression}

The progression of flower development was recorded by periodically counting the number of open blossoms in each orchard. At the pink-bud stage, four branches from each tree were randomly selected, with each having at least 20 floral buds, which were counted as the initial bud number. Number of open flowers (anthers visible) were counted every $1-3$ days until all buds entered the full bloom stage ( $100 \%$ of flowers are open). Blooming rate was calculated as the ratio of open blossoms to the initial bud number of buds per tree, and the flowering date $\left(\mathrm{F}_{50}\right)$ for each treatment was determined when the blooming rate reached $50 \%$.

\subsection{Evaluation of Fruit Set, Fruit Size and Tree Injury}

In the 'Redhaven' and 'Sunhigh' orchards, the numbers of fruits on the marked branches were counted 2, 4, and 6 weeks after full bloom. Fruit set (\%) was calculated as the number of fruit set divided by the number of flowers times 100. Fruit size was evaluated in the 'Redhaven' and 'Sunhigh' orchards at 2, 4 and 6 weeks after full bloom (WAFB). A total of 10 fruits were randomly selected from each tree and the diameter of each was recorded by measuring the widest part of each fruit using a digital caliper.

To evaluate the magnitude of damage induced by ethephon treatments, we collected and weighed the dead branches (mostly 1- and 2-year-old branches) from each experimental tree of 'Redhaven' and 'Sunhigh' 6 WAFB (Figure S1). 


\subsection{Determination of Bud Cold Hardiness}

The cold hardiness of the peach buds was estimated using the differential thermal analysis (DTA). In this analysis, the buds are subject to progressive freezing until the symplastic water in the bud tissues freezes to release the heat of fusion, which is recorded as low temperature exotherm (LTE). The cold hardiness of the 'Redhaven' buds was examined on the control and ethephon-500 ppm trees at 200, 600, 1000, 1250, and $1400 \mathrm{CH}(16.4$, $33.8,56.2,68.4$, and $74.6 \mathrm{CP}$, respectively). In this assessment, three one-year-old shoots, each from a replicate tree of control and ethephon treatments were harvested from the 'Redhaven' orchard and kept on ice until processed. Flower buds were excised from shoots with a small portion of subtending shoot tissue attached. One cut end of each bud was coated with ice nucleation active (INA) bacteria to ensure freezing of the bulk water [23]. One or two buds from each treatment were placed onto each of the nine sample cells, which are arranged on a sample tray; each cell was covered by a tight-fitting foam (Brock University Electronics Shop, Brock University, St. Catherines, ON, Canada) (Figure S2A,B). The trays were then placed in the Tenney Junior Environmental Test Chamber, Model TJR, with a Watlow F4 controller (Thermal Product Solutions, New Columbia, PA, USA) (Figure S2C). Data were acquired by a Keithley 2700 Multimeter/Data Acquisition System (Keithley, Cleveland, OH, USA), which was driven by the Bud Freezer software (v 1.2, Brock University). The temperature profile of the environmental chamber was programmed as follows: equilibration for $1 \mathrm{~h}$ at $4{ }^{\circ} \mathrm{C}$, ramp to $-35^{\circ} \mathrm{C}$ in $-2{ }^{\circ} \mathrm{C} / \mathrm{h}$ decrements, soak $3 \mathrm{~h}$ at $-35{ }^{\circ} \mathrm{C}$, ramp to $4{ }^{\circ} \mathrm{C}$ with $5{ }^{\circ} \mathrm{C} / \mathrm{h}$ increments, hold at $4{ }^{\circ} \mathrm{C}$. The voltage signal from each bud sample was recorded at a $1 \mathrm{~s}$ interval as the temperature was progressively lowered and LTE was detected as a peak when the symplastic water in the tested buds started to freeze (Figure S2D).

\subsection{Quantification of Phytohormones}

Plant hormones were analyzed using a high-performance liquid chromatography coupled with a mass spectrometry (LC-MS) system. To prepare for hormone quantification and gene expression analysis (see next section), dormant floral buds of 'Redhaven' were sampled at eight time points based on $\mathrm{CH}$ accumulation of 20, 200, 400, 600, 800, and $1000(0.6$, $16.4,27.6,33.8,48.9$, and 56.2 CP, respectively) and GDH accumulation of 1000 and 3000, which correspond to calendar dates of 14 October, 11 November, 27 November, 9 December, 27 December of 2019, and 15 January, 14 February, and 12 March of 2020, respectively. Collected buds were immediately frozen in liquid nitrogen and kept at $-80^{\circ} \mathrm{C}$ until further processing. Bud samples from each replicate were homogenized in liquid nitrogen using a Geno/Grinder. About $100 \mathrm{mg}$ ground sample was weighed and mixed with 5 times $(w / v) 80 \%$ ice-cold HPLC-grade methanol, vortexed for $1 \mathrm{~min}$, and kept at $4{ }^{\circ} \mathrm{C}$ in the dark for $3 \mathrm{~h}$. Samples were centrifuged at $14,000 \mathrm{rpm}$ at $4{ }^{\circ} \mathrm{C}$ for $20 \mathrm{~min}$, and the supernatants were centrifuged at $4{ }^{\circ} \mathrm{C}$ for another $10 \mathrm{~min}$ to further remove the remaining debris. The supernatants were completely dried with a SpeedVac and resuspended in $100 \mu \mathrm{L}$ of $80 \%$ methanol. Samples were injected into the ZORBAX Eclipse Plus C18 column (mobile phase A: water containing $0.1 \%$ acetic acid; mobile phase B: acetonitrile containing $0.1 \%$ acetic acid) coupled to an Agilent 6490 Triple Quadrupole LC-MS System with AJS technology. Quantification of GA9, ABA, JA, and JA-Ile was performed as described by Seo et al. [24].

\subsection{RNA Extraction and Gene Expression Analyses}

Total RNA was extracted from bud samples using a CTAB method previously described by Sherif et al. [25]. All RNA extracts were DNase treated and purified using the RNA clean and concentrator kit (Zymo Research, Irvine, CA, USA). For cDNA synthesis, $2 \mu \mathrm{g}$ of purified RNAs was reverse transcribed using the cDNA Synthesis Kit (Applied Biosystem, Foster City, CA, USA) according to the manufacturer's instructions. The quantitative real-time PCR (qPCR) reactions were performed using the CFX Connect Real-Time System (Bio-Rad, Hercules, CA, USA) and the SsoFast EvaGreen Supermix (BioRad, USA). The primers were designed using Primer3Plus (https:/ /www.bioinformatics.nl/cgi-bin/ 
primer3plus / primer3plus.cgi, accessed on 24 March 2020) to target the key genes in the biosynthesis pathways of plant hormones ABA, which include two 9-cis-epoxycarotenoid dioxygenase genes (NCED2 and NCED3); GA, including two GA 20-oxidases (GA20-OX1 and GA20-OX2); ethylene, including ACC-synthase (ACS) and ACC-oxidase (ACO); and JA, including linoleate 13S-lipoxygenase (13-LOX), allene oxide synthase (AOS), allene oxide cyclase (AOC), OPDA-reductase 3 (OPR3), and JA-amino synthetase (JAR) (Table S1). The $\beta$-Actin gene (Prupe.6G163400.1) was used as the endogenous control for gene expression normalization. The expression of each gene was calculated relative to the gene expression of the control sample $(20 \mathrm{CH})$, using the CFX manager software (Bio-Rad). The normalized relative expression data represent the mean $( \pm$ ) standard error (SE) of three biological replicates, each including three technical replicates.

\subsection{Data Analyses}

The cold hardiness data were processed by the Bud Processor software (v1.0, Brock University) that allows visualization of temperature (independent variable) versus voltage (dependent variable). The low temperature exotherms (LTEs) were then identified and stored for statistical analysis by the Bud LTE software (v 1.0, Brock University). The Bud LTE software presented the data for the mean \pm standard deviation of LTE10, LTE50, and LTE90, which denote the temperatures at which 10, 50, and $90 \%$ of the buds are killed, respectively. In particular, LTE50 corresponds to the cold hardiness (Hc) [26].

All statistical analyses in this study were performed using R version 3.6.3 (R Core Team, 2020). One-way ANOVA was conducted for each experiment to test the ethephon effect on the metrics of interest; Tukey HSD was used for multiple comparisons of significant effects from ANOVA models $(p<0.05)$.

\section{Results}

\subsection{Accumulation of $\mathrm{CH}$ and $\mathrm{GDH}$}

Temperature data recorded in the 'Redhaven' orchard were used to show the cumulative $\mathrm{CH}$ and GDH and several major events in this study (Figure 1). $\mathrm{CH}$ accumulation began on 7 October 2019 and continued to increase progressively thereafter, showing a pattern similar to that of chilling portion $(\mathrm{CP})$ based on the dynamic model. Ethephon was applied at $50 \%$ leaf fall (LF) which corresponded to $40 \mathrm{CH}$. Chilling requirement for the control of 'Redhaven' was fulfilled at $1046 \mathrm{CH}$. The GDH accumulation started on 23 January 2020 and increased rapidly, reaching approximately 4500 on 18 March, when the control started blooming.

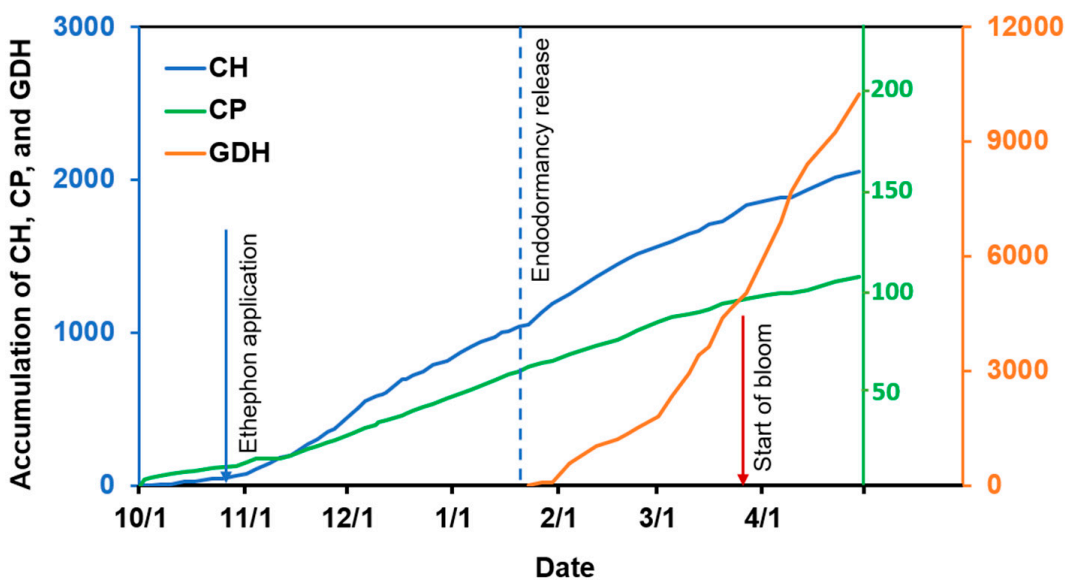

Figure 1. Accumulation of chilling hours $(\mathrm{CH})$, chilling portions $(\mathrm{CP})$, and growing degree hours $(\mathrm{GDH})$ in the 'Redhaven' orchard. Major events are indicated with arrows. CH accumulation began on 7 October 2019, ethephon was applied on 24 October 2019, endodormancy of the control ended on 22 January 2020, GDH accumulation began on 23 January 2020, flowering of the control began on 18 March. 


\subsection{Ethephon Accelerated Leaf Abscission}

The induction of leaf abscission has been linked to the use of ethephon. The defoliation effects of ethephon were evaluated on 'Redhaven' one week after application. The results showed that ET-300 and $-500 \mathrm{ppm}$ treatments induced $60.1 \%( \pm 4.8)$ and $55.7 \%( \pm 4.2)$ of leaf abscission, respectively (Figure 2A), nearly two times more than the control $(p<0.01)$. In contrast, no significant defoliation was observed in the ET-100 ppm treatment, indicating that ethephon effects on tree defoliation is concentration-dependent.
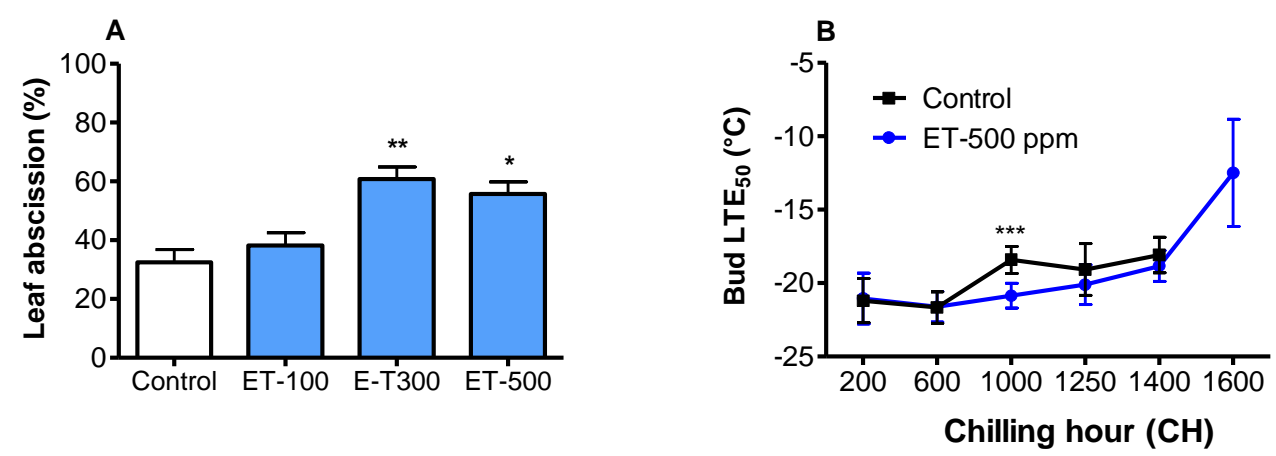

Figure 2. Effects of ethephon (ET) on leaf abscission and cold hardiness of 'Redhaven'. (A) Leaf abscission 7 days after ethephon applications. Bars represent the mean \pm SE of three biological replicates (10 branches/replicate); (B) LTE 50 (temperature at which 50\% of the buds are killed) of flower buds during endodormancy and ecodormancy. Each point represents the mean $\mathrm{LTE}_{50} \pm \mathrm{SE}$ of 12-18 individual buds. Asterisks *, **, and *** indicate significance at $p<0.05,0.01$, and 0.001 , respectively. $\mathrm{CH}$ accumulation corresponds to calendar dates of 15 November and 11 December of 2019, and 5 January, 6 February, 14 February, and 4 March of 2020, respectively.

\subsection{Ethephon Improved Cold Hardiness}

The ethephon effects on the cold hardiness of dormant buds were evaluated by computing the $\mathrm{LTE}_{50}$ (the freezing temperatures at which $50 \%$ of the flower buds are killed) of the control and the ET-500 ppm treatment (Figure 2B). The LTE 50 was well below $-20{ }^{\circ} \mathrm{C}$ for both the control and ET treatment at 200 and $600 \mathrm{CH}$, and then increased gradually starting at $1000 \mathrm{CH}$, at which the $\mathrm{LTE}_{50}$ of ET treatment was significantly lower than that of the control $(p<0.001)$. At $1600 \mathrm{CH}$, the ET treatment lost $9.1^{\circ} \mathrm{C}$ of cold hardiness, compared to its maximum cold hardiness at $600 \mathrm{CH}\left(-21.6^{\circ} \mathrm{C}\right)$, whereas the $\mathrm{LTE}_{50}$ of the control buds was undetectable, indicating a complete loss of cold hardiness at this point.

\subsection{Ethylene Production in Leaves and Buds}

Leaves are believed to be the primary organs that convert exogenously applied ethephon to ethylene $[27,28]$. Our results indicated that ethylene production in leaves after ethephon applications at 10 and $90 \% \mathrm{LF}$ reached its maximum level of 3.7 and $4.4 \mathrm{nmol} \cdot \mathrm{g}^{-1} \cdot \mathrm{h}^{-1}$ one day after application, both of which are greater than the respective controls (Figure 3A). The peak rates of ethylene production were followed by a rapid decline in both treatments. During the first three days after application, there was no significant difference in ethylene production between 10 and $90 \%$ LF treatments, but they were all significantly higher than the control. Ethylene production in the $10 \%$ LF treatment decreased to $1.2 \mathrm{nmol} \cdot \mathrm{g}^{-1} \cdot \mathrm{h}^{-1}$ six days after application and remained low thereafter. Due to accelerated leaf abscission, leaves became unavailable 15 and 3 days after ethephon application at 10 and $90 \%$ LF, respectively. 

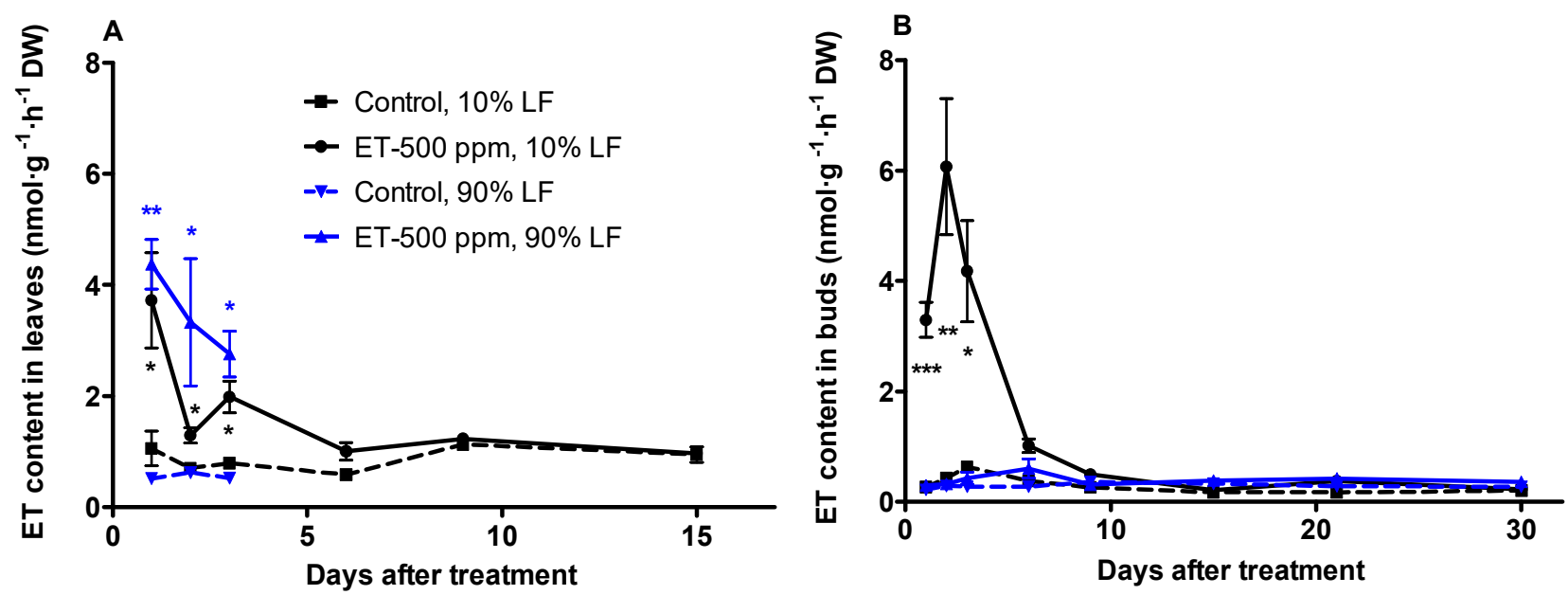

Figure 3. Dynamics of ethylene levels in leaves (A) and buds (B) of 'Redhaven' in response to ethephon application of $500 \mathrm{ppm}$ at 10 and 90\% LF. Ethylene levels in leaves were measured until the complete abscission. Each point represents the mean \pm SE of size $n=3$. Asterisks ${ }^{*}{ }^{* *}$, and ${ }^{* * *}$ indicate significant difference between ET treatments and the control at $p<0.05,0.01$, and 0.001, respectively. ET, ethephon; LF, leaf fall; DW, dry weight.

We also measured the rate of ethylene production in flower buds up to 30 days after ethephon application, when no difference between treatment and the control could be detected. When ethephon was applied at the $10 \% \mathrm{LF}$, ethylene production in buds peaked two days after application, reaching $6.07 \mathrm{nmol} \cdot \mathrm{g}^{-1} \cdot \mathrm{h}^{-1}$, approximately 14 times higher than the control (Figure 3B). After this peak, ethylene levels decreased quickly and returned to the control level nine days after application. In contrast to the high ethylene production in the 10\% LF treatment, ethylene levels in the 90\% LF application remained extremely low, approximating the levels of the control during the course of the experiment.

\subsection{Ethephon Increased Chilling and Heat Requirements}

The effects of ethephon on chilling requirements was assessed by recording the $\mathrm{CH}$ and CP that were needed for $50 \%$ of the floral buds to break dormancy under forcing conditions (Table 1). In 'Redhaven', the floral buds of ethephon treatments generally required more chilling than the control to break endodormancy, with ET-500 ppm requiring 131 more $\mathrm{CH}(5.6 \mathrm{CP})$ than the control $(p<0.05)$ to achieve cold requirements. Though the ethephon treatments of 100 and 300 ppm also increased the CR when compared to the control, the differences were not significant. Similar increase of CR was also observed in 'Sunhigh', in which the CR of the three ethephon treatments were all significantly higher than that of the control, with CR increases ranging from 287 to $340 \mathrm{CH}$ (16.2 to $21.5 \mathrm{CP}$ ), and no significant differences among the ethephon treatments.

Table 1. Chilling requirements of peach cultivars as affected by autumn-applied ethephon.

\begin{tabular}{cccccc}
\hline Cultivar & Treatment & CR $^{\mathbf{x}}$ & Date $^{\mathbf{y}}$ & \multicolumn{2}{c}{ Days $^{\mathbf{z}}$} \\
\hline & Control & $1046(62.2)$ & 22 January & 88 & $\mathrm{a}$ \\
Redhaven (P. persica) $)$ & ET-100 ppm & $1112(65.9)$ & 26 January & 92 & $\mathrm{ab}$ \\
& ET-300 ppm & $1147(67.3)$ & 28 January & 94 & $\mathrm{ab}$ \\
& ET-500 ppm & $1177(67.8)$ & 29 January & 95 & $\mathrm{~b}$ \\
& Control & $805(46.9)$ & 28 December & 94 & $\mathrm{a}$ \\
Sunhigh (P. persica) & ET-10\% & $1145(68.4)$ & 27 January & 124 & $\mathrm{~b}$ \\
& ET-50\% & $1115(65.6)$ & 26 January & 123 & $\mathrm{~b}$ \\
& ET-100\% & $1092(63.1)$ & 25 January & 122 & $\mathrm{~b}$
\end{tabular}

$\overline{\mathrm{X}}$ Chilling requirements (CR) is displayed as the number of $\mathrm{CH}$ and $\mathrm{CP}$ (in parenthesis). ${ }^{\mathrm{Y}}$ Date at which $50 \%$ of buds released from endodormancy. ${ }^{\mathrm{z}}$ Number of days from the beginning of chilling accumulation (7 October) until release of endodormancy. All comparisons are made within each cultivar with significant level at 0.05 , and significant differences apply to both $\mathrm{CH}$ and Days. 
Heat requirement (HR) was calculated as the accumulation of GDH from the date when the CR was fulfilled in each treatment to the date when $50 \%$ of flower buds were in bloom (Table 2). In 'Redhaven', the ethephon treatments exhibited concentration-dependent effects on increasing HR, in which the three concentrations of 100, 300, and $500 \mathrm{ppm}$ extended HR by 245,578 , and $901 \mathrm{GDH}$, respectively, with HR of the ET-500 ppm treatment being significantly higher $(p<0.05)$ than the control, but no significant differences were found among ethephon treatments. Similarly, significant HR increases were found in all the three ethephon-treated 'Sunhigh' trees $(p<0.05)$. HR increases appeared to depend on the level of leaf fall (LF), with ET-10\% LF showing the highest HR (882 GDH), followed by ET-50\% (696 GDH), and ET-100 \% (583 GDH), but there was no significant difference among ethephon treatments.

Table 2. Heat requirements and flowering date of two peach cultivars as affected by autumnapplied ethephon.

\begin{tabular}{cccccc}
\hline Cultivar & Treatment & HR $^{\mathbf{X}}$ & Flowering $_{\left(\mathbf{F}_{\mathbf{5 0}}\right)^{\mathbf{y}}}$ & \multicolumn{2}{c}{ Days $^{\mathbf{z}}$} \\
\hline & Control & 4682 & 23 March & 60 & $\mathrm{a}$ \\
Redhaven (P. persica) & ET-100 ppm & 4927 & 26 March & 63 & $\mathrm{ab}$ \\
& ET-300 ppm & 5260 & 28 March & 65 & $\mathrm{~b}$ \\
& ET-500 ppm & 5583 & 29 March & 66 & $\mathrm{~b}$ \\
& Control & 4960 & 24 March & 61 & $\mathrm{a}$ \\
Sunhigh (P. persica) & ET 10\% & 5842 & 30 March & 67 & $\mathrm{~b}$ \\
& ET 50\% & 5656 & 29 March & 66 & $\mathrm{~b}$ \\
& ET 100\% & 5543 & 28 March & 65 & $\mathrm{~b}$ \\
\hline
\end{tabular}

$\overline{\mathrm{X}}$ Heat requirements (HR) is displayed as the number of growing degree hours (GDH). ${ }^{\mathrm{Y}}$ Date at which $50 \%$ of buds were at the open-blossom stage $\left(\mathrm{F}_{50}\right) .{ }^{\mathrm{z}}$ Number of days after breaking of endodormancy until flowering (F50). All comparisons are made within each cultivar with significant level at 0.05 , and significant differences apply to both $\mathrm{CH}$ and Days.

\subsection{Ethephon Delayed Bloom in Peach}

In general, ethephon application induced remarkable bloom delay in peach in a concentration-timing and application-timing dependent manner (Figure 4A,B). In 'Redhaven', the flowering period lasted from mid-March to the beginning of April, with flowering date $\left(\mathrm{F}_{50}\right)$ of control occurring on 23 March (Table 2). The three ethephon treatments resulted in progressive delays of the flowering date by 3-6 days, with the ET-300 and ET-500 ppm treatments showing significant bloom delays compared to the control (Figure 4C). Comparably, 'Sunhigh' exhibited 4-6 days delay in flowering date in all ethephon treatments $(p<0.05)$, with the ET-10\% LF inducing the largest delay and ET-100\% LF the lowest (Figure $4 \mathrm{D}$ ). 
A
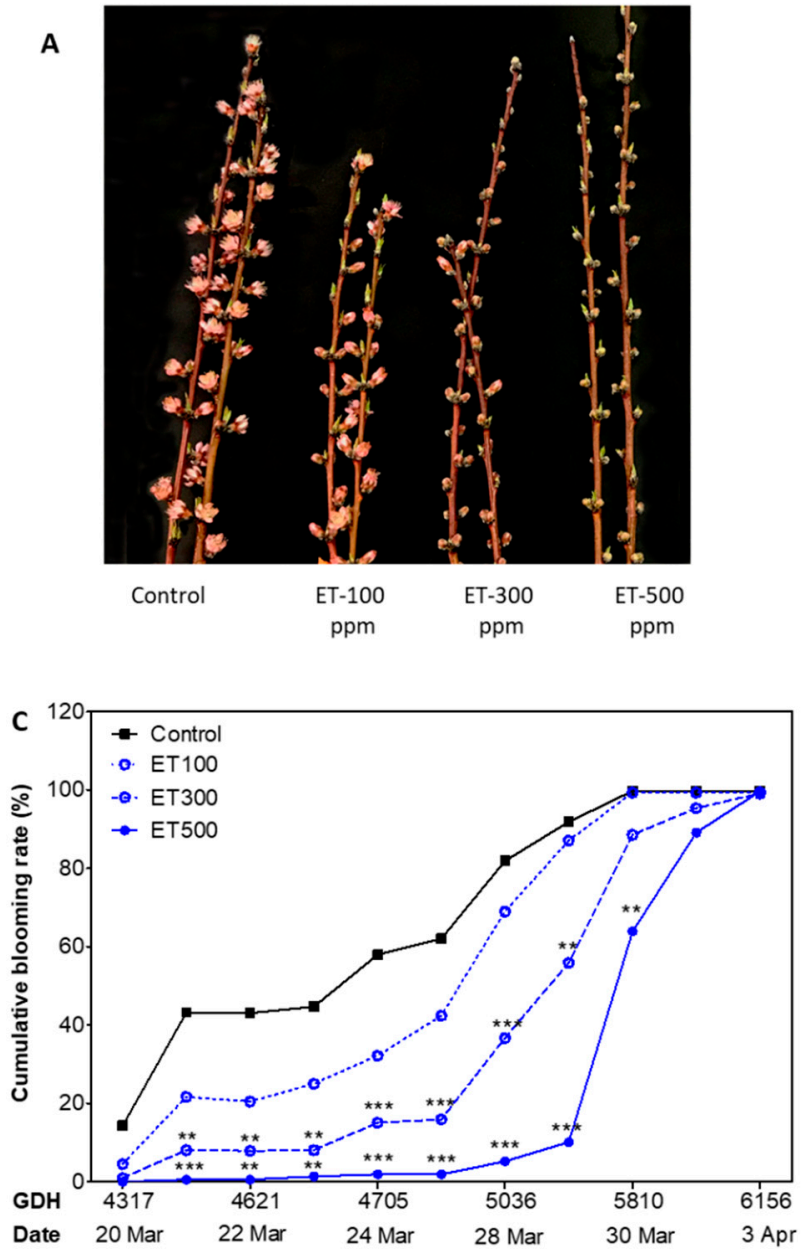
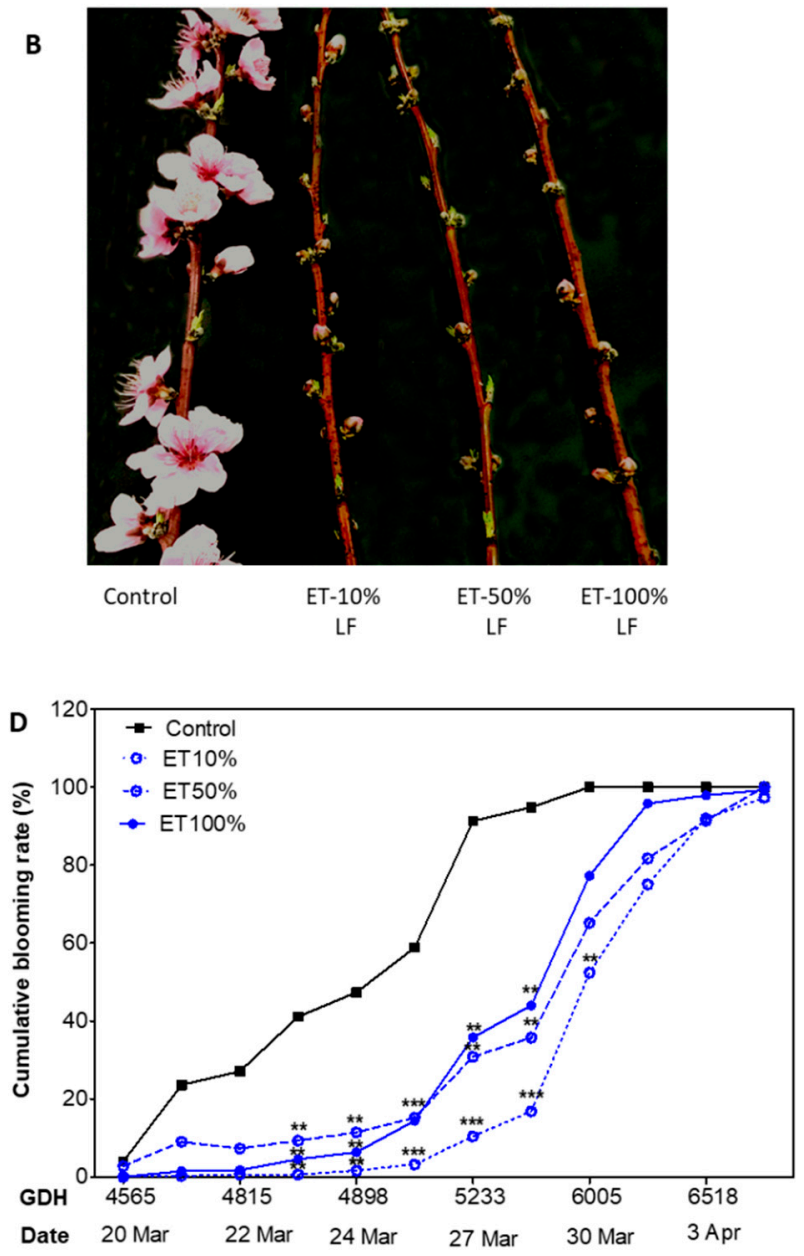

Figure 4. Bloom-delaying effects of ethephon (ET) on peach cultivars. Comparison of blooming between the untreated controls and ethephon treatments of 'Redhaven' (A) and 'Sunhigh' (B), with photos taken at full bloom of the controls (24 March 2020). Blooming progression of 'Redhaven' (C) and 'Sunhigh' (D) as affected by ethephon, and blooming rate calculated as the ratio of number of flowers to the number of buds on tagged branches. Each point represents the mean of size $n=12$. Asterisks ${ }^{* *}$ and ${ }^{* * *}$ indicate significant difference between ET treatments and the control at $p<0.01$ and 0.001 , respectively. ET, ethephon; LF, leaf fall.

\subsection{Ethephon Effects on Fruit Set and Fruit Size}

In this study, ethephon effects on percent fruit set and fruit size were evaluated 2, 4 , and 6 weeks after full-bloom (WAFB). Fruits were thinned 7 WAFB and no further data of fruit set and fruit size were collected at harvest. In 'Redhaven', percent fruit set decreased gradually in all treatments and control, reaching $60-75 \%$ at 6 WAFB. No significant differences in the fruit set were observed between the control and ethephon treatments at any time point (Figure 5A). In 'Sunhigh', except for ET-10\% LF treatment, a dramatic drop in fruit set was observed in the control and ET-50\% and ET-90\% treatments at 4 WAFB, which ranged from 70 to $98 \%$ (Figure 5B). Such abnormal fruitlet abscission could be presumably attributed to a spring frost that occurred in the 'Sunhigh' orchard between 2 and 3 WAFB on 17 April when the fruit size was about $5.5 \mathrm{~mm}$. The lowest temperature of this frost reached $-2.8^{\circ} \mathrm{C}$ and lasted for more than 90 min (Figure S3). 

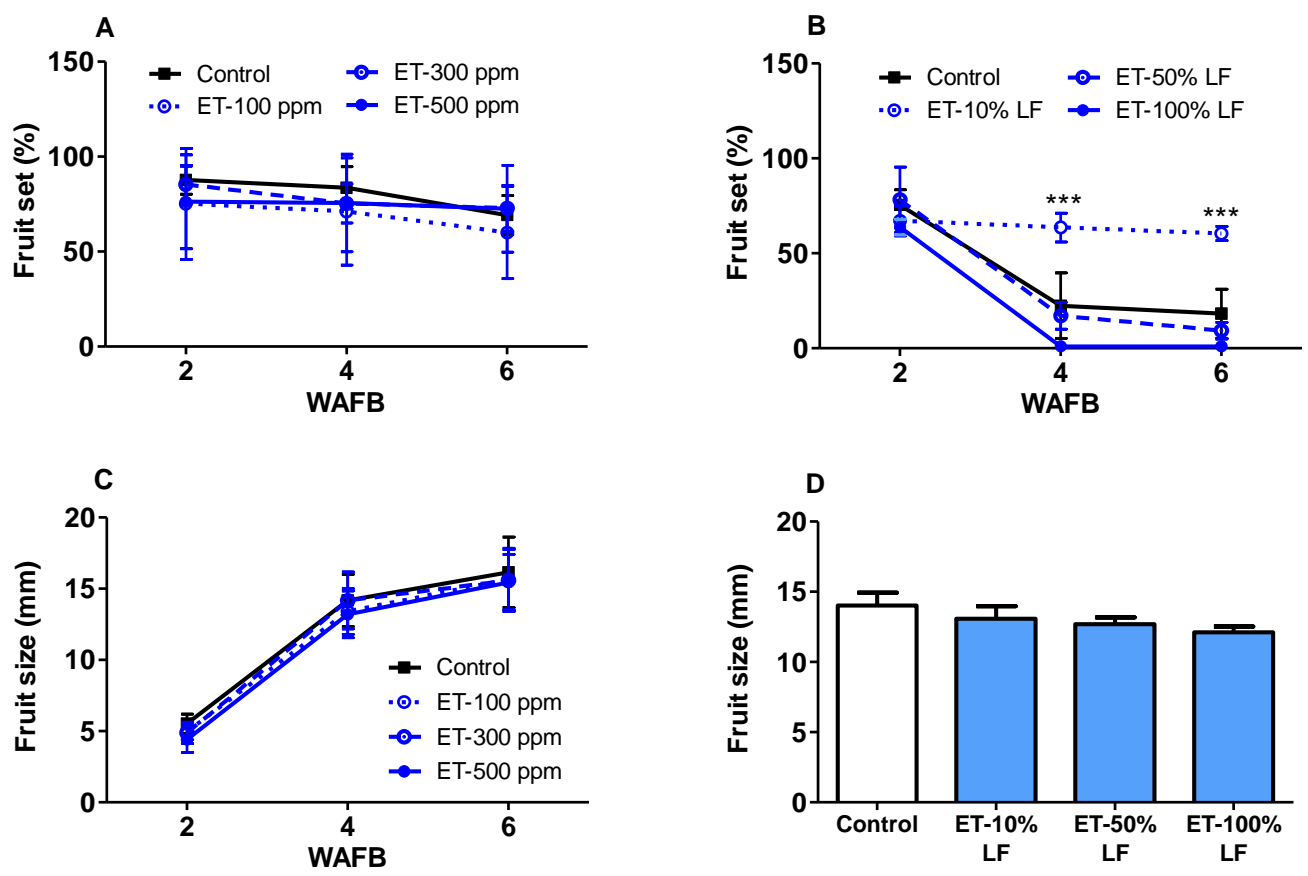

Figure 5. Ethephon effects on fruit set and fruit size of peach cultivars. Fruit set (\%) of 'Redhaven' (A) and 'Sunhigh' (B) was evaluated 2, 4, and 6 WAFB. Fruit size of 'Redhaven' (C) was measured 2, 4, and 6 WAFB and fruit size of 'Sunhigh' (D) was measured 6 WAFB. Each point or bar represents mean \pm SE, each of size $n=12$ for fruit set, and $n=30$ for fruit size. Asterisks ${ }^{* * *}$ represent significant difference between ET treatment and the control at $p<0.001$. ET, ethephon; LF, leaf fall; WAFB, weeks after full bloom.

The fruit size of 'Redhaven' and 'Sunhigh' was estimated by measuring the equatorial diameters of the tested fruits during the first 6 WAFB. In 'Redhaven', the fruit size of the control increased from $5.3 \mathrm{~mm}$ at 2 WAFB to $15.3 \mathrm{~mm}$ at 6 WAFB, with the ET-500 ppm treatment being $1.1 \mathrm{~mm}$ less than the control $(p<0.05)$ at $2 \mathrm{WAFB}$, and no difference between the control and the ethephon treatments found at 4 or 6 WAFB. In 'Sunhigh', the fruit size measured 6 WAFB was similar between the control and ethephon treatments, with the average diameter ranging 12.1 to $14.0 \mathrm{~mm}$, showing a weak negative correlation between fruit size and earliness of ethephon application (Figure 5D).

\subsection{Tree Injuries Associated with Ethephon}

In this study, the weight $(\mathrm{g})$ of dead branches collected 6 WAFB from each treated and control tree was used to estimate the magnitude of injury induced by ethephon. In 'Redhaven', the weight of dead branches per tree in control averaged at $171 \mathrm{~g}( \pm 50.1)$ and was significantly lower than that of the ET-300 ppm treatment $(p=0.039)$, but not different from ET-100 or ET-500 ppm (Figure 6A). In 'Sunhigh', the highest weight of dead branches was found in the ethephon $10 \% \mathrm{LF}$ treatment (Figure $6 \mathrm{~B})$, averaging at $103.7 \mathrm{~g}( \pm 9.9)$ and was significantly higher than that of the control $(p=0.03)$. These results suggest that early applications of ethephon at high concentration ( $500 \mathrm{ppm})$ is likely damaging. 

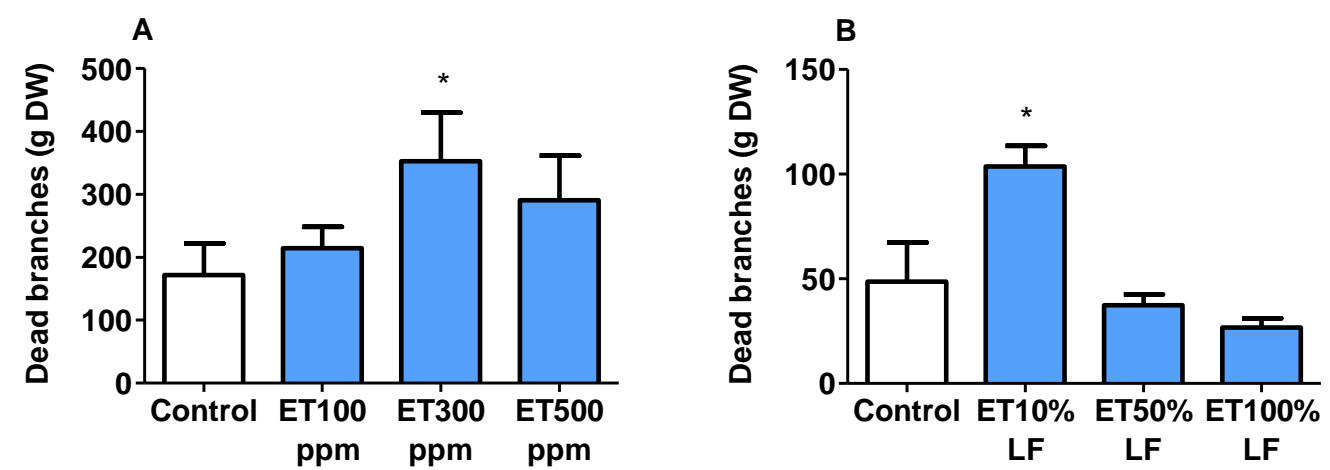

Figure 6. Ethephon effects on injury of peach 'Redhaven' (A) and 'Sunhigh' (B). Injury was evaluated by weighing the total dead branches from each tree 6 WAFB. Each bar represents the mean + SE of size $n=6$. Asterisk * indicates significant difference between ET treatment and the control at $p<0.05$. ET, ethephon; LF, leaf fall.

\subsection{Phytohormone Accumulation Profiles during Dormancy}

Phytohormones play a critical role in regulating the processes of dormancy and flowering [29]. To test the hypothesis that fall-applied ethephon affects CR, HR, and bloom time through modulation of phytohormone biosynthesis and accumulation during dormancy, the levels of some major phytohormones were quantified in the floral buds throughout the bud dormancy cycle in relation to $\mathrm{CH}$ and GDH. In this study, we quantified the levels of phytohormones in the control and ET-500 ppm treatment of 'Redhaven' peach trees at 200, 400, 600, 800, and $1000 \mathrm{CH}$; and 1000 and $3000 \mathrm{GDH}$.

Of the four nongaseous major phytohormones, the levels of auxin, cytokinin, and all bioactive forms of gibberellin (GA) in the bud tissues were below the detectable level with the LC-MS system. The hormones successfully quantified were abscisic acid (ABA), GA9, a precursor of GA4, which is a bioactive gibberellin, and jasmonic acid (JA) and its conjugate Jasmonoyl-Isoleucine (JA-Ile). During the dormancy to the preflowering period, the changes in ABA levels were similar between the control and the ethephon treatments, with the highest level detected at $200 \mathrm{CH}$. ABA levels decreased gradually with chilling accumulation, reaching its lowest level at $800 \mathrm{CH}$ and remained low until $3000 \mathrm{GDH}$, except for a moderate rise at $1000 \mathrm{CH}$ (Figure 7A). Moderate fluctuations were observed in the levels of GA9 during dormancy, which reached its peak levels of 1.3 and $1.1 \mathrm{ng} \cdot \mathrm{g}^{-1}$ in control and ethephon treatment at $1000 \mathrm{CH}$ and declined slightly at $1000 \mathrm{GDH}$ (Figure 7B). It was also noticeable that GA9 levels declined abruptly to nearly zero at $3000 \mathrm{GDH}$. In contrast to GA9, the levels of JA were undetectable from $200 \mathrm{CH}$ through $1000 \mathrm{GDH}$, and abruptly increased to 4.1 and $2.8 \mathrm{ng} \cdot \mathrm{g}^{-1}$ at $3000 \mathrm{GDH}$ for the control and ethephon treatment, respectively (Figure 7C). Similarly, JA-Ile levels remained less than $6 \mathrm{ng} \cdot \mathrm{g}^{-1}$ at all timepoints before $3000 \mathrm{GDH}$ and spiked dramatically to 116.8 and $99.1 \mathrm{ng} \cdot \mathrm{g}^{-1}$ at $3000 \mathrm{GDH}$ for the control and ET treatment, respectively (Figure 7D). No significant differences were detected in the hormone levels between the control and ET treatment at any timepoint. 

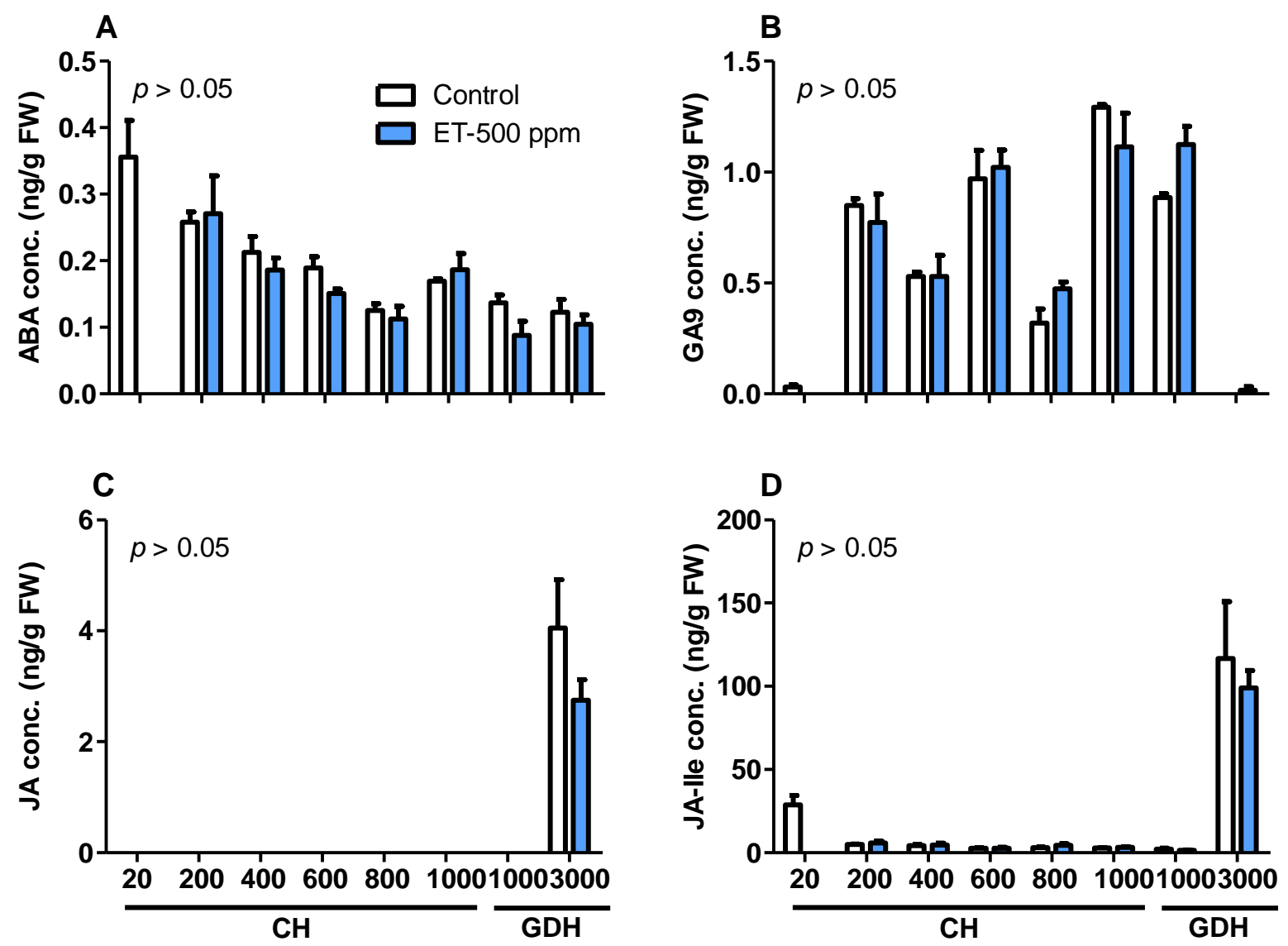

Figure 7. Hormone concentration of ABA (A), GA9 (B), JA (C), and JA-Ile (D) in floral buds of peach 'Redhaven' during endodormancy and ecodormancy. Each bar represents the mean \pm SE of three biological replicates; $p$-values indicate comparisons between the control and ethephon treatment at $500 \mathrm{ppm}$. The $\mathrm{CH}(200,600,800$, and 1000) and GDH (1000 and 3000) accumulation corresponds to the sampling dates of 11 November, 27 November, 9 December, and 27 December of 2019, and 15 January, 14 February, and 12 March of 2020, respectively. ABA, abscisic acid; GA, gibberellin; JA, jasmonic acid; and JA-Ile, Jasmonoyl isoleucine; $\mathrm{CH}$, chilling hour; GDH, growing degree hour; conc., concentration; FW, fresh weight.

\subsection{Expression of Genes That Regulate ABA, GA, ET and JA Biosynthesis}

To further examine the effects of ethephon treatments on hormone de novo biosynthesis in the buds, the expression profiles of several key genes responsible for biosynthesis of $\mathrm{GA}, \mathrm{ABA}, \mathrm{ET}$, and JA were investigated in 'Redhaven' in relation to $\mathrm{CH}$ and GDH. The results indicated that the expression of ABA synthetic gene NCED2 was low at $200 \mathrm{CH}$ for both the control and ethephon-500 ppm treatment, reaching its highest levels at $400 \mathrm{CH}$ and $600 \mathrm{CH}$ for control and ET treatment, respectively, followed by a rapid decline and remained relatively low until $3000 \mathrm{GDH}$ (Figure 8A). Expression of NCED3 was similar to NCED2, except for the highest expression of control and ET treatment both occurred at $600 \mathrm{CH}$ (Figure 8B). For GA biosynthesis pathways, transcript levels of GA20-OX1 and GA20-OX2 showed low levels through the endodormancy period, and increased gradually with GHD accumulation, reaching a peak at $3000 \mathrm{GHD}$ without showing significant differences between the control and ET treatment (Figure $8 C, D$ ). The two genes that regulate ethylene biosynthesis, $A C S$ and $A C O$, showed similar expression patterns: both remained low from $200 \mathrm{CH}$ through $1000 \mathrm{GDH}$ and increased rapidly at $3000 \mathrm{GDH}$ (Figure 8E,F). In particular, the ACS expression level in the control was two times higher than that of the ET treatment $(p<0.05)$. 

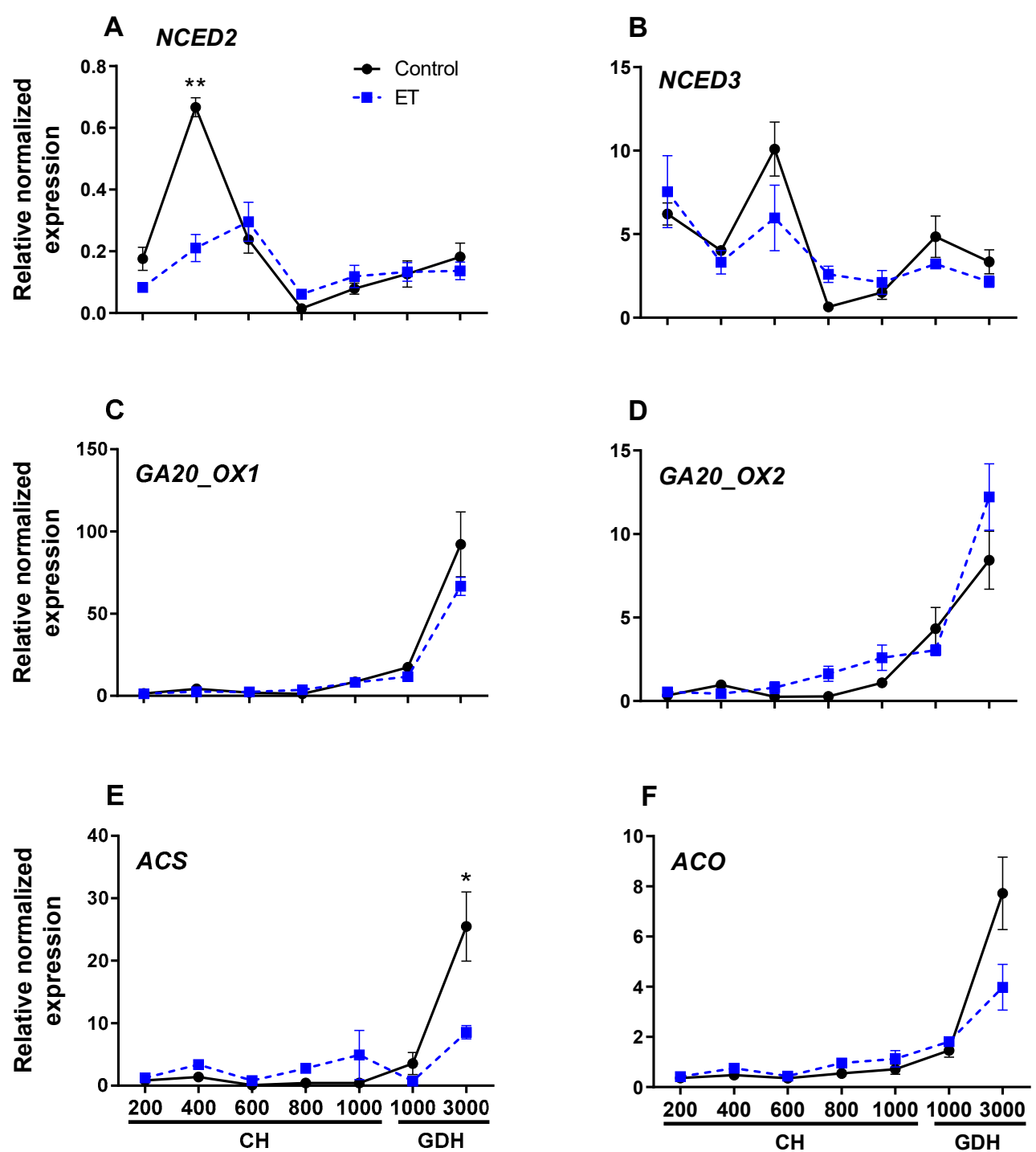

Figure 8. Relative normalized expression of genes that regulate biosynthesis of ABA (A,B), GA $(\mathbf{C}, \mathbf{D})$, and ethylene $(\mathbf{E}, \mathbf{F})$ in the floral buds of peach 'Redhaven'. Expression of each gene was normalized to that of $\beta$-Actin and expressed relative to the control sample $(20 \mathrm{CH})$. Each point represents the mean \pm SE of three biological replicates, each with three technical replicates. Values marked with asterisks * and ${ }^{* *}$ are significantly different at $p<0.05$ and 0.01, respectively. NCED, 9-cisepoxycarotenoid dioxygenase; GA20-OX, GA 20-oxidase; ACS, 1-aminocyclopropane-1-carboxylic acid (ACC)-synthase; and ACO, ACC-oxidase. $\mathrm{CH}$, chilling hour; GDH, growing degree hour. Refer to Figure 7 legend for the sampling dates that correspond to the $\mathrm{CH}$ and $\mathrm{GDH}$ accumulation.

To unravel the transcriptional regulation of JA and JA-Ile during dormancy, we examined the transcriptional activity of the genes that control the key steps in the biosynthesis JA and JA-Ile. JA biosynthesis starts from an 18-carbon fatty acid ( $\alpha$-linolenic acid, 18:3), which undergoes multistep oxygenation, cyclization, and reduction that are sequentially catalyzed by linoleate 13S-lipoxygenase (13-LOX), allene oxide synthase (AOS), allene oxide cyclase (AOC), and OPDA-reductase 3 (OPR3); in the final step, JA is converted to the most bioactive form jasmonoyl-isoleucine (JA-Ile) by JA-amino synthetase (JAR) [30] (Figure 9F). Our results indicated that the relative expression of LOX (Figure 9A) remained low from $200 \mathrm{CH}$ through $1000 \mathrm{GDH}$ and increased rapidly at $3000 \mathrm{GDH}$ to 6.2 and 3.7 for control and ET treatment, respectively, with no significant difference between the two. The expression of $A O S$ (Figure 9B) in the control and ET treatment were both low at $200 \mathrm{CH}$ and through $1000 \mathrm{GDH}$. At $3000 \mathrm{GDH}$, AOS transcript levels in the control increased abruptly, 
whereas the expression of the ethephon treatment decreased slightly, being about $10 \%$ of the control $(p<0.01)$. Nearly identical transcript dynamics of $A O C$ were found between the control and ethephon treatment throughout all the timepoints (Figure 9C), in which both remained extremely low until $3000 \mathrm{GDH}$, when both exhibited an abrupt increase. Similar expression pattern was also found for OPR3 (Figure 9D), in which the expression increased only slightly at $3000 \mathrm{GDH}$. The expression of JAR (Figure 9E) appears to lack a clear pattern. JAR transcripts in the control remained low from $200 \mathrm{CH}$ to $1000 \mathrm{GDH}$, except for a noticeable increase at $400 \mathrm{CH}$, which was higher than the ET treatment $(p<0.01)$, and another clear peak at $3000 \mathrm{GDH}$. In the ET treatment, JAR transcript levels were slightly higher than that of the control during dormancy period, but the differences were not statistically significant.
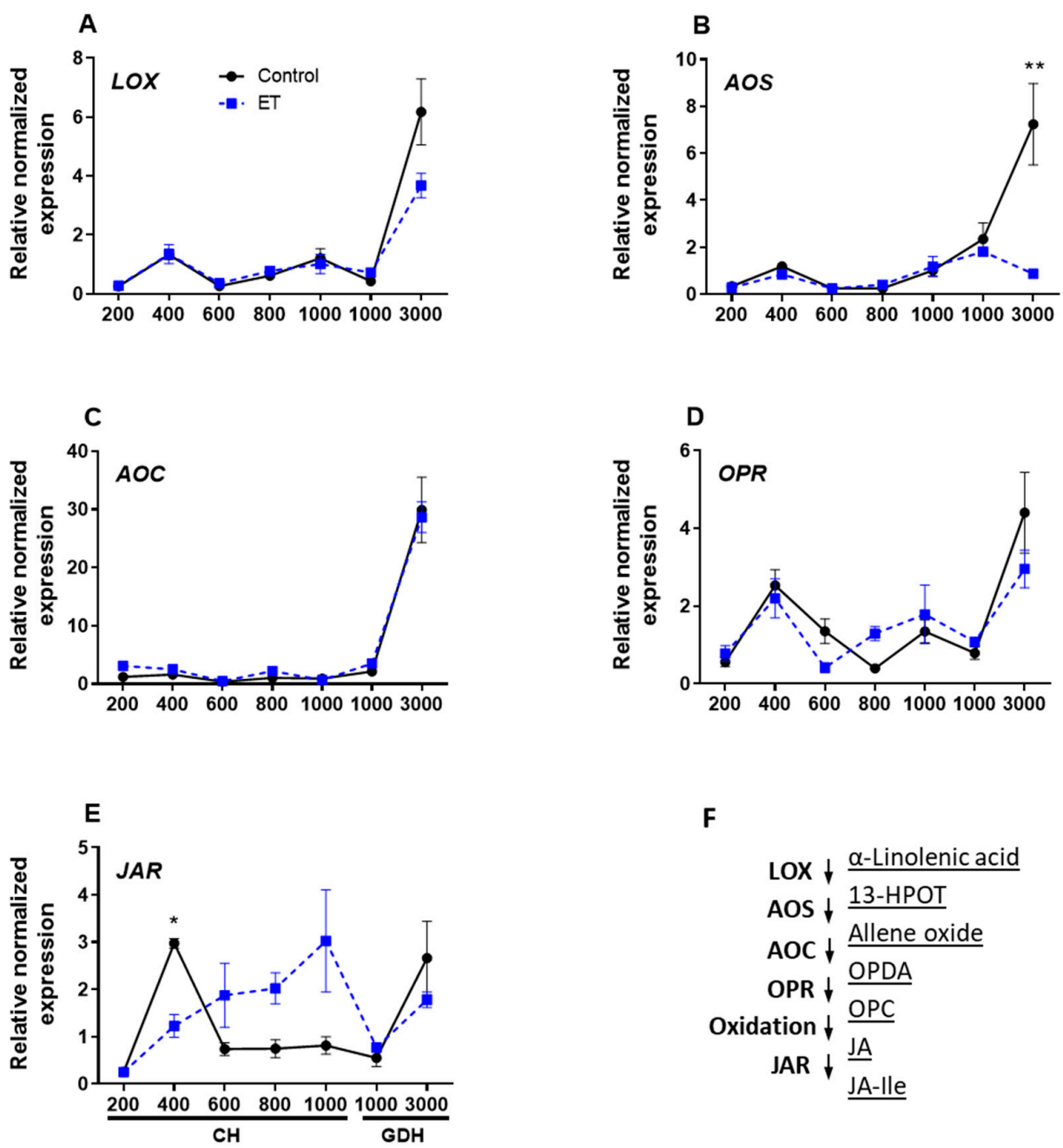

$\mathbf{F}$

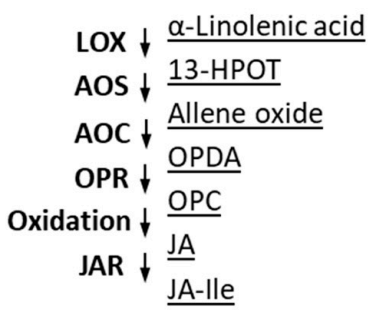

Figure 9. Relative normalized expression of JA synthetic genes in peach 'Redhaven' during bud dormancy (A-E) and the schematic diagram of the JA biosynthesis pathway (F). Expression of each gene was normalized to that of $\beta$-Actin and expressed relative to the control sample $(20 \mathrm{CH})$. Each point represents the mean $\pm \mathrm{SE}$ of three biological replicates, each with technical replicates. Values marked with asterisks * and ${ }^{* *}$ are significantly different at $p<0.05$ and 0.01 , respectively. Enzymes that sequentially catalyze the synthesis of JA and conjugation of JA-Ile are listed on the left of the downward arrows, and intermediate products are given on the right (F). LOX, lipoxygenase; AOS, allene oxide synthase; AOC, allene oxide cyclase; OPR, OPDA reductase; JAR, JA-amino synthetase; OPC, cyclopentane-1-octanoic acid; OPDA: oxo-phytodienoic acid; JAR, JA-amino acid synthetase. $\mathrm{CH}$, chilling hour; $\mathrm{GDH}$, growing degree hour. Refer to Figure 7 legend for the sampling dates that correspond to the $\mathrm{CH}$ and GDH accumulation. 


\section{Discussion}

Our study extensively examined the ethephon effects on several key physiological aspects during the dormancy-bloom period of two peach cultivars. Through field trials and laboratory experiments, we showed that fall applications of ethephon significantly modulated chilling and heat requirements, acclimation/deacclimation of dormant buds, cold hardiness, bloom date, and overall tree health. Hormonal quantification of ethephontreated and untreated trees revealed that JA biosynthesis pathway may play an essential role in triggering budburst and flowering in peach, and gene expression profiles also confirmed that de novo JA biosynthesis in the buds could be also affected by the ethephon treatment.

\subsection{Floral Bud Phenology and Cold Hardiness as Modulated by Ethephon}

Chilling and heat requirements have been shown to be essential factors that dictate flowering date in deciduous woody perennials, although some disagreement exists regarding their relative importance [31-35]. Ethephon effects on increasing cold and heat requirements have been reported in several studies. Using container-grown peach trees, Durner and Gianfagna [11] showed that 'Redhaven', when treated with 100 ppm ethephon, required three more weeks of chilling exposure to release from endodormancy compared to the control. Similarly, our results indicate ethephon extended both CR and HR in peach, in a concentration and application time-dependent manner. Since chilling requirements were largely fulfilled before the onset of heat accumulation in all treatments, the extent by which ethephon affected bloom delay should only be explained by the increased HR.

In the ethylene production experiment, our results showed that application of ethephon induced rapid increase of ethylene in leaves, confirming the notion that leaves are the primary organs that absorb and convert ethephon $[27,28]$. This was further confirmed in flower buds where ethylene levels were significantly higher when ethephon was applied at $10 \%$ compared to $90 \% \mathrm{LF}$, asserting that leaves are required for effective uptake of ethephon that is subsequently converted and distributed to other organs. Notably, ethephon applied at 10\% LF stimulated an ethylene spike in the flower buds two days after application, followed by a rapid decrease. This result is consistent with a recent study [36] in which ethylene evolution in peach flowers and fruitlets exhibited similar dynamics in response to foliar application of ethephon, which induces fruit abscission. Likely, it is this transient increase of ethylene in the flower buds that exert effects on the subsequent phenological and physiological processes.

Our results showed that ethephon treatment significantly delayed bloom date, and the extent of the delay depended on concentrations and time of application. Essentially, ethephon was more effective when applied at the early stage of leaf fall and at higher concentrations (Figure 3). Our results agree with several other reports that have shown varying effects of ethephon on bloom delay in response to different concentrations and application timings. For instance, Coston and Krewer [37] reported that 120 ppm ethephon delayed bloom in peach by 5 and 9 days, whereas 500 ppm ethephon delayed bloom by up to 18 days. In another study, fall applications of ethephon at 50, 200, and $400 \mathrm{ppm}$ delayed the full bloom date of nectarine by 6-15 days [38]. The reason why fall-applied ethephon delays bloom is still unclear. Some reports indicated that ethephon applications can retard the growth of flower buds and floral organs [37], and this delayed growth could be linked to the increase of ABA levels in the dormant buds induced by ethephon [39]. Indeed, ethylene has been shown to promote the synthesis of $\mathrm{ABA}[40,41]$ and to activate ABA signaling pathway [42] as well. However, our results, cannot support this ethephon-induced ABA hypothesis as we did not observe any significant effects for ethephon on the levels of ABA and its biosynthetic genes at any time point during the bud dormancy of 'Redhaven' peach (Figures 7A and 9A,B).

Recently, Liu and Sherif [4] implied that the ethephon-induced bloom delay could be a result of elevated stress response. If exogenous ethephon application is to be sensed by the plant as a stress signal, the extended dormancy period and delayed bloom would be advantageous for the fitness and survival for the perennial species in face of unfavorable 
environmental conditions [43]. There is emerging evidence that supports this hypothesis. Gummosis is the exudation of polysaccharide gum that is produced primarily in response to various stresses [44], and ethephon has been implicated in the induction of gummosis in stone fruits [45]. In addition, the treatment with ethylene immediate precursor 1-aminocyclopropane-1-carboxylic acid (ACC) has been found to trigger cell cycle arrest in Arabidopsis [46] and leafy spurge [42], in a way comparable to stress responses. In fact, growth arrest is a prerequisite for the initiation of dormancy, and hastened growth cessation has been associated with intensified dormancy and delayed bud burst [47]. It is thus likely that fall-applied ethephon stimulates an array of stress responses, which are retained throughout the dormancy period until the budburst and flowering.

Flower buds contain reproductive primordia, and their ability to withstand the freezing temperatures during winter and spring determines the yield potential and fruit quality. In this study, the cold hardiness of 'Redhaven' flower buds was examined in control and the $500 \mathrm{ppm}$ ethephon treatment during dormancy and through the prebloom stage. The steady rise of hardiness occurred approximately when the $\mathrm{CR}$ was fulfilled in control $(1046 \mathrm{CH})$ and the ethephon treatment $(1177 \mathrm{CH})$. This loss of cold hardiness, or deacclimation is a function of many external and internal factors, such as ambient temperatures, photoperiod, water availability, metabolism status, and dormancy status [48]. Change in cold hardiness in peach is closely related to the soluble sugar content and the accumulation of a $60 \mathrm{kDa}$ dehydrin protein [49]. Our results indicate that cold hardiness is highly dependent on the depth of dormancy and was improved by ethephon applications (Figure 2B), which is generally consistent with other reports on grapevine [50], peach [6], and magnolia (Magnolia wufengensis) [51]. Peach buds acquire cold hardiness primarily via the supercooling of intracellular water, and it was shown that ethephon enhances supercooling in peach buds through increasing soluble sugar content [52]. Ethylene has been implicated in the development of chilling tolerance. With an ethylene-insensitive mutant of tomato (Lycopersicon esculentum), [53] demonstrated that chilling tolerance can be enhanced by increased ethylene biosynthesis. The mechanism by which ethephon enhances the cold tolerance in plants has also been implied in the activation of ethylene response factor $(E R F)$ genes, which activate several cold-response pathways, including antioxidation, ice nucleation activity, and production of osmotic proteins [54,55]. In Magnolia shoots, ethephon was shown to reduce the water content and facilitate the accumulation of free proline [51], a beneficial amino acid that imparts stress tolerance, including cold [56,57].

\subsection{Ethephon Effects on Fruit Set, Fruit Size and Tree Health}

Strong fruit set is critical for orchard profitability and sustainability. In this study, the fruit set was not significantly influenced by ethephon in 'Redhaven', when applied at concentrations up to $500 \mathrm{ppm}$ (Figures 5A and 6B). In 'Sunhigh', as the fruit set was dramatically reduced in control along with the 50 and $100 \%$ LF treatments, only slight reduction was observed in the in $10 \%$ LF treatment. This remarkable decline in fruit set (\%) in the 'Sunhigh' orchard was likely due to the spring frost that occurred 2 WAFB (17 April 2020), which reached $-2.8^{\circ} \mathrm{C}$ and lasted for $90 \mathrm{~min}$ (Figure S3). Such frosts were not recorded in the 'Redhaven' orchard, probably because of its higher elevation ( $7 \mathrm{~m}$ higher) compared to the 'Sunhigh' orchard, making it less prone to cold air accumulation at night. The critical temperature that kills 10 and $90 \%$ of post bloom flowers within 30 min are -2.2 and $-3.9^{\circ} \mathrm{C}$, respectively (https: / / www.canr.msu.edu/resources / picture-table-critical-springtemperatures-for-tree-fruit-bud-development-stages, accessed on 15 May 2021). Therefore, the frosts that inflicted the 'Sunhigh' orchard were severe enough to damage or kill the developing fruitlets that averaged at $5.5 \mathrm{~mm}$ in diameter. The unaffected fruit set (\%) found in ethephon treatment at $10 \% \mathrm{LF}$ should reflect the improvement of cold hardiness in this treatment. The higher effectiveness of ethephon applied at 10\% LF than later stages is likely because leaves are the primary site where ethephon is absorbed and quickly hydrolyzed to release ethylene after entering the leaf cells [58], and more leaves apparently accelerate this process. 
The final fruit size at harvest is predominantly determined by the cell number, whereas cell size only has minor effects [59]. In this study, the fruit size of 'Redhaven' and 'Sunhigh' was measured in the first six weeks after bloom (42 DAB), at which the differences of fruit size between treatments and the control would adequately reflect the relative fruit size at harvest. Our results showed there was no significant difference between the ethephon treatments and the control in either orchard. This finding is similar to the observation by Irving [38] that ethephon had no adverse effects on fruit size of nectarine at harvest. In contrast, some studies indicated that fall-applied ethephon causes reduction in the fruit size in peach [60] and sweet cherry. The final fruit size is highly dependent on many factors such as fruit cell number/size, pre-thinning/post-thinning crop load, rate of fruit development, and those factors that may potentially confound with the use of ethephon, such as spring frosts and ethephon-induced injury. The discrepancies in the findings may arise from any of these factors, and accurate examination of fruit size will require these confounding factors to be kept constant or eliminated.

Tree injury is one of the common issues that has been linked to ethephon applications [10,37]. Our results indicated that both ethephon concentration and application timing are important factors that contribute to the damaging impact of ethephon, as more damage to tree branches was observed with high concentrations and early stage of leaf fall (Figure 6B). Since ethephon enters plants through the leaf epidermis, applications at early stage of LF, when more leaves are still attached, would elicit higher ethylene response. Branch damage is only one aspect of the ethephon-related injury, and whether such damage would affect cumulative tree yield over several years warrants further investigation.

\subsection{Endogenous Hormonal Changes Associated with Bloom Delay}

ABA has been regarded as the fundamental cornerstone in the regulatory network of bud dormancy. In this study, ABA levels was high at the beginning of endodormancy, and gradually decreased thereafter with the accumulation of chilling units (Figure 7). This result supports the notion that $\mathrm{ABA}$ is responsible for dormancy induction and is consistent with observations reported in grapevine [61], peach [62], and pear (Pyrus pyrifolia) [63]. ABA accumulation pattern during dormancy cycle was also supported by the transcript levels of ABA biosynthesis genes, NCED2 and NCED3 (Figure 8). However, it can be noted that expression level of these genes somehow lagged behind the changes in ABA levels. This discrepancy between ABA increase and NCED transcriptional induction was also observed in grapevine [61], which suggests that high ABA levels may be induced by NCED paralogs other than NCED2 and NCED3 at the endodormancy initiation. It is also worth noting that $\mathrm{ABA}^{\prime}$ 's role as dormancy mediator is not necessarily involved in the ethephon-mediated bloom delay. In fact, the level of ABA and its biosynthetic genes showed no significant difference between the control and the ethephon-treated trees at any time point. This result indicates that ethephon may exert its effects on CR, HR, and bloom delay through mechanisms that are independent of ABA.

Gibberellins (GA) comprise a large group of diterpenoid tetracyclic acids, in which only a small subset possesses bioactivity. In GA biosynthesis, GA9 is synthesized from GA12 by a series of oxidation catalyzed by GA20-oxidase (GA20ox) followed by oxidation by GA3-oxidase (GA3OX) to from the bioactive GA4. It has been shown that GA4 plays a role in the regulation of Arabidopsis floral initiation through modulating LFY transcription [64]. Application of GA4 has been shown to induce bud burst in Populus [65] and bud dormancy release in Japanese apricot [66]. It is unexpected that of the many forms of GA, only the level of GA9 was detectable (Figure 7B). GA9 level was relatively high during endodormancy and ecodormancy, and decreased dramatically at $3000 \mathrm{GDH}$. As an inactive form, GA9 may serve as a GA reserve during dormancy when the active forms of GA are not in need. The rapid decrease of GA9 at $3000 \mathrm{GDH}$, therefore, could reflect the rapid oxidation of GA9 to form GA4, which in turn, triggers bud burst and flowering. Further investigation is needed to validate this hypothesis. The upregulation of GA20ox at 3000 GDH suggests the de novo synthesis of GA in floral buds (Figure 8C,D). Indeed, 
the increase of GA20ox3 expression was concomitant with the release of endodormancy in grapevine [67].

JA has complex effects in flower opening and development of floral organs [68]. As the inhibitory effect of JA on flowering was found in morning glory (Pharbitis nil) [69] and Arabidopsis [68], its promotive effect was showed in tomato (Solanum lycopersicum) [70]. In addition to its functions on flowering, JA has also been implicated in dormancy release of seeds, which is exemplified by a transient increase of JA preceding germination [71,72]. Direct evidence of JA's role in bud dormancy is scarcely documented. In analyzing the transcriptome changes in Populus, Howe et al. [73] exhibited that several genes that regulate JA synthesis were downregulated at the onset of dormancy, whereas two LOX genes were upregulated at the release of dormancy. JA gains its hormonal activity via conjugation, catalyzed by JAR, with isoleucine to form JA-isoleucine (JA-Ile) [74]. In the present study, the levels of JA and JA-Ile peaked 7-10 days before the initial flowering date in both the control and ethephon-treated trees (Figure $7 \mathrm{C}, \mathrm{D}$ ), indicating that JA may play a role in inducing bud burst and bloom. The gene expression analysis revealed that the expression of several genes regulating JA synthesis such as LOX, AOS, AOC, and OPR3 were all upregulated concomitant with the rise of endogenous JA levels prior to flowering (Figure 9A-D), indicating that JA may be de novo synthesized and regulated transcriptionally in the buds. This increase of JA and JA-Ile levels prior to flowering is in line with the finding by Ionescu et al. [75], who demonstrated that JA and JA-Ile levels in sweet cherry increased remarkably before budburst, along with the upregulation of several JA biosynthesis genes. The authors also found that JA-Ile production was induced by the treatment of hydrogen cyanide, an agrochemical that is used commercially to induce budbreak in many deciduous fruit trees. It is also important to note that, the JA and JA-Ile levels in the ethephon treatment were 47.3 and $17.8 \%$ lower than those in the control, respectively (Figure 7C,D), but the differences were not statistically significant. However, this result may still be indicative of reduction of JA synthesis in ethephon treatments, as the expression of AOS in the ethephon treatment was only $10 \%$ of that of the control (Figure 9B), and AOS controls a key step in JA biosynthesis [76].

Some molecular evidence has shown that both ethylene biosynthesis and signaling are involved in the induction of dormancy. Treatment with the ethylene antagonist, 2,5-norbornadiene (NBD), promotes dormancy release in potato microtuber [77], and impairment in ethylene perception inhibits the dormancy initiation in chrysanthemum (Chrysanthemum morifolium), even after treated with ethephon [78]. The finding that a suite of ethylene signaling genes (e.g., ETR2, EIN3, EIN4, and ERFs) in Populus is upregulated under dormancy-inducing conditions [79] reinforces the role of ethylene in dormancy establishment. In higher plants, ACC synthase (ACS) and ACC oxidase (ACO) are the two pacesetting enzymes in ethylene biosynthesis, with their expression stringently controlled [80]. In this study, the upregulation of ACS and ACO at 3000 GDH indicate an increase in ethylene biosynthesis (Figure 8E,F), which agrees with the notion that ethylene plays an important role in dormancy release and flowering [29,75,81]. It can be noted the ACS and ACO transcript levels were lower in the ethephon treatment than the control, suggesting that ethephon treatment in the fall may result in an eventual reduction in ethylene synthesis toward the end of ecodormancy, thereby inducing bloom delay.

\section{Conclusions}

In this study, we demonstrated that fall application of ethephon impacted several aspects of peach floral bud phenology, including accelerated leaf fall, extended chilling accumulation period, increased heat requirements, improved cold hardiness, and delayed bloom date. In general, ethephon effects on these aspects depended on the concentration and application timing, with high concentrations and early fall applications being more effective. However, such application regimes may be coupled with damages to peach trees and potentially negate the beneficial effects of ethephon in bloom delay, which could subsequently restrain its commercial use for frost mitigation. The hormonal and molecular 
data collected in this study presented evidence that ethephon-exerted effects on floral bud phenology are unlikely reliant on ABA and its biosynthetic pathway. Therefore, it is rather unlikely that ABA would serve as a plausible ethephon alternative to delay bloom in stone fruits. On the other hand, our data signifies the role of JA as a potential regulator of budburst and bloom in peach; however, further research is required to validate these observations and investigate the underlying crosstalk between JA, ethylene, and other dormancy-related pathways. Our findings portray a new perspective in interpreting horticultural traits in the light of biochemical and molecular data, and explain, at least partially, the role of ethylene in dormancy and flowering phenology. This research also reinforces the use of $\mathrm{CH}$ and GDH as universally applicable markers to schedule sample collections and record phenological events. Using these markers in future studies will enable parallel and comparative analyses of physiological and omics data to fine-tune the inherently complex pathways governing bud dormancy in peach and other deciduous woody perennials. Ethephon-mediated bloom delay could serve as a useful model for investigating the genetic, epigenetic, and biochemical mechanisms underlying flowering time regulation in peach. Understanding these aspects is not only essential for developing climate-resilient germplasm through breeding and biotechnology, but it can also help in formulating products and strategies to modulate the bloom dates of existing cultivars, hence avoiding potential spring freezes.

Supplementary Materials: The following are available online at https:/ /www.mdpi.com/article/10 .3390/plants10071266/s1, Figure S1. Evaluation of ethephon-induced injury on peach trees; Figure S2. Low Temperature Exotherm (LTE) analysis of cold hardiness; Figure S3. Temperatures 2 weeks after full bloom in the orchards of 'Redhaven' and 'Sunhigh'; Table S1. Gene-specific primer sequences used for relative gene expression analysis of peach 'Redhaven' using qPCR.

Author Contributions: J.L. performed the majority of the experiments, analyzed the data, and wrote the manuscript. M.T.I. and S.S. assisted with sample collection, tissue preparation, and gene expression analyses. P.R. and P.P.K. quantified the phytohormones in peach bud tissues. T.S.A. assisted with the cold hardiness experiments. S.M.S. conceived and designed the experiments, edited the manuscript, and oversaw the study. All authors have read and approved the final manuscript.

Funding: This project was funded by Virginia Department of Agriculture and Consumer Services (418953) and the Virginia's Agricultural Council (449846).

Data Availability Statement: The data presented in this study are available in the supplementary materials.

Acknowledgments: The authors would like to thank Sara Pitcock, Chester Allen, and Kenneth Savia for their assistance in orchard management, chemical sprays, and data collection.

Conflicts of Interest: The authors declare that the research was conducted in the absence of any commercial or financial relationships that could be interpreted as a potential conflict of interest.

\section{References}

1. Vitasse, Y.; François, C.; Delpierre, N.; Dufrêne, E.; Kremer, A.; Chuine, I.; Delzon, S. Assessing the effects of climate change on the phenology of European temperate trees. Agric. For. Meteorol. 2011, 151, 969-980. [CrossRef]

2. Vitasse, Y.; Schneider, L.; Rixen, C.; Christen, D.; Rebetez, M. Increase in the risk of exposure of forest and fruit trees to spring frosts at higher elevations in Switzerland over the last four decades. Agric. For. Meteorol. 2018, 248, 60-69. [CrossRef]

3. Hoffmann, H.; Rath, T. Future Bloom and Blossom Frost Risk for Malus domestica Considering Climate Model and Impact Model Uncertainties. PLoS ONE 2013, 8, e75033. [CrossRef]

4. Liu, J.; Sherif, S.M. Combating Spring Frost with Ethylene. Front. Plant Sci. 2019, 10, 1408. [CrossRef] [PubMed]

5. Nzokou, P.; Nikiema, P. The Influence of Three Plant Growth Regulators on Susceptibility to Cold Injury Following Warm Winter Spells in Fraser Fir [Abies fraseri (Pursh) Poir] and Colorado Blue Spruce (Picea pungens). HortScience 2008, 43, 742-746. [CrossRef]

6. Durner, E.F. Dormant Pruning and Fall Ethephon Application Influence Peach Pistil Hardiness. J. Am. Soc. Hortic. Sci. 1995, 120, 823-829. [CrossRef]

7. Grijalva-Contreras, L.R.; Martínez-Díaz, G.; Macías-Duarte, R.; Robles-Contreras, F. Effect of ethephon on almond bloom delay, yield, and nut quality under warm climate conditions in northwestern Mexico. Chil. J. Agric. Res. 2011, 71, 34-38. [CrossRef]

8. Moghadam, E.G.; Mokhtarian, A. Delaying Apricot (cv. Shahroudi) Flower Induction by Growth Regulators Application. J. Appl. Sci. 2006, 6, 266-269. [CrossRef] 
9. Pahwa, K.; Ghai, N. Effect of ethylene on physiological and biochemical parameters in different crop plants-A review. J. Appl. Nat. Sci. 2015, 7, 1064-1069. [CrossRef]

10. Crisosto, C.H.; Miller, A.N.; Lombard, P.B.; Robbins, S. Effect of Fall Ethephon Applications on Bloom Delay, Flowering, and Fruiting of Peach and Prune. HortScience 1990, 25, 426-428. [CrossRef]

11. Durner, E.F.; Gianfagna, T.J. Ethephon Prolongs Dormancy and Enhances Supercooling in Peach Flower Buds. J. Am. Soc. Hortic. Sci. 1991, 116, 500-506. [CrossRef]

12. Crisosto, C.H.; Lombard, P.B.; Fuchigami, L.H. Effect of Fall Ethephon and Hand Defoliation on Dormant Bud Ethylene Levels, Bloom Delay, and Yield Components of 'Redhaven' Peach. Acta Hortic. 1987, 201, 203-212. [CrossRef]

13. Funt, R.; Ferree, D. Ethephon Induced Bloom Delay of Peach Trees, Ohio USA. Acta Hortic. 1986, 163-170. [CrossRef]

14. Krewer, G.; Nesmith, D.S.; Williamson, J.; Maus, B.; Mullinix, B. Ethephon for Bloom Delay of Rabbiteye and Southern Highbush Blueberries. Small Fruits Rev. 2005, 4, 43-57. [CrossRef]

15. Lang, G.A. Dormancy: A new universal terminology. HortScience 1987, 22, 817-820.

16. Fan, S.; Bielenberg, D.G.; Zhebentyayeva, T.N.; Reighard, G.L.; Okie, W.R.; Holland, D.; Abbott, A.G. Mapping quantitative trait loci associated with chilling requirement, heat requirement and bloom date in peach (Prunus persica). New Phytol. 2010, 185, 917-930. [CrossRef] [PubMed]

17. Weinberger, J.H. Chilling requirement of peach varieties. J. Am. Soc. Hortic. Sci. 1950, 56, 122-128.

18. Richardson, E.A.; Seeley, S.D.; Walker, D.R. A model for estimating the completion of rest for Redhaven and El-berta peach trees. HortScience 1974, 9, 331-332.

19. Fishman, S.; Erez, A.; Couvillon, G.A. The temperature dependence of dormancy breaking in plants: Mathematical analysis of a two-step model involving a cooperative transition. J. Theor. Biol. 1987, 124, 473-483. [CrossRef]

20. Anderson, J.; Richardson, E.; Kesner, C. Validation of Chill Unit and Flower Bud Phenology Models for 'Montmorency' Sour Cherry. Acta Hortic. 1986, 184, 71-78. [CrossRef]

21. Beauvieux, R.; Wenden, B.; Dirlewanger, E. Bud Dormancy in Perennial Fruit Tree Species: A Pivotal Role for Oxidative Cues. Front. Plant Sci. 2018, 9, 657. [CrossRef] [PubMed]

22. Devitt, M.L.; Stafstrom, J.P. Cell cycle regulation during growth-dormancy cycles in pea axillary buds. Plant Mol. Biol. 1995, 29, 255-265. [CrossRef] [PubMed]

23. Wisniewski, M.; Lindow, S.E.; Ashworth, E.N. Observations of Ice Nucleation and Propagation in Plants Using Infrared Video Thermography. Plant Physiol. 1997, 113, 327-334. [CrossRef] [PubMed]

24. Seo, M.; Jikumaru, Y.; Kamiya, Y. Profiling of Hormones and Related Metabolites in Seed Dormancy and Germination Studies. Methods Mol. Biol. 2011, 773, 99-111. [CrossRef]

25. Sherif, S.M.; Shukla, M.R.; Murch, S.J.; Bernier, L.; Saxena, P.K. Simultaneous induction of jasmonic acid and disease-responsive genes signifies tolerance of American elm to Dutch elm disease. Sci. Rep. 2016, 6, 21934. [CrossRef] [PubMed]

26. Wisniewski, M.; Lightner, G.; Davis, G.; Schiavone, M. System configuration for microcomputer-controlled, low-temperature differential thermal analysis. Comput. Electron. Agric. 1990, 5, 223-232. [CrossRef]

27. Olien, W.B.; Bukovac, M.J. The effect of temperature on rate of ethylene evolution from ethephon and from ethephon-treated leaves of sour cherry. J. Am. Soc. Hortic. Sci. 1978, 103, 199-202.

28. Flore, J.A.M.J.B. Factors influencing absorption of 14C(2-chloroethyl-phosphonic acid by leaves of cherry. J. Am. Soc. Hortic. Sci. 1982, 107, 965-968.

29. Liu, J.; Sherif, S.M. Hormonal Orchestration of Bud Dormancy Cycle in Deciduous Woody Perennials. Front. Plant Sci. 2019, 10, 1136. [CrossRef] [PubMed]

30. Wasternack, C.; Hause, B. Jasmonates: Biosynthesis, perception, signal transduction and action in plant stress response, growth and development. An update to the 2007 review in Annals of Botany. Ann. Bot. 2013, 111, 1021-1058. [CrossRef] [PubMed]

31. Ruiz, D.; Campoy, J.; Egea, J. Chilling and heat requirements of apricot cultivars for flowering. Environ. Exp. Bot. 2007, 61, 254-263. [CrossRef]

32. Alburquerque, N.; García-Montiel, F.; Carrillo, A.; Burgos, L. Chilling and heat requirements of sweet cherry cultivars and the relationship between altitude and the probability of satisfying the chill requirements. Environ. Exp. Bot. 2008, 64, 162-170. [CrossRef]

33. Alonso, J.M.; Ansón, J.M.; Espiau, M.T.; Sociasi, C.R. Determination of endodormancy break in almond flower buds by a correlation model using the average temperature of different day intervals and its application to the estimation of chill and heat requirements and blooming date. J. Am. Soc. Hortic. Sci. 2005, 130, 308-318. [CrossRef]

34. Egea, J.; Ortega, E.; Martínez-Gómez, P.; Dicenta, F. Chilling and heat requirements of almond cultivars for flowering. Environ. Exp. Bot. 2003, 50, 79-85. [CrossRef]

35. Fadón, E.; Fernandez, E.; Behn, H.; Luedeling, E. A Conceptual Framework for Winter Dormancy in Deciduous Trees. Agronomy 2020, 10, 241. [CrossRef]

36. Torres, E.; Giné-Bordonaba, J.; Asín, L. Thinning flat peaches with ethephon and its effect on endogenous ethylene production and fruit quality. Sci. Hortic. 2021, 278, 109872. [CrossRef]

37. Coston, D.C.; Krewer, G.W.; Elkner, T.E.; Williamson, J.G.; Sims, E.T.J. Chemical treatments to delay bloom in peach prunus persica. J. Am. Soc. Hortic. Sci. 1985, 110, 874-877. 
38. Irving, D.E. 'Fantasia' nectarine: Effects of autumn-applied ethephon on blossoming and cropping. Exp. Agric. 1987, 15, 67-72. [CrossRef]

39. Crisosto, C.H. Fall Ethephon Delays-Bloom in 'Redhaven' Peach by Delaying Flower Differentiation and Development during Dormancy. J. Am. Soc. Hortic. Sci. 1989, 114, 881-884.

40. Grossmann, K.; Hansen, H. Ethylene-triggered abscisic acid: A principle in plant growth regulation? Physiol. Plant. 2001, 113, 9-14. [CrossRef]

41. Rodrigo, M.-J.; Alquezar, B.; Zacarías, L. Cloning and characterization of two 9-cis-epoxycarotenoid dioxygenase genes, differentially regulated during fruit maturation and under stress conditions, from orange (Citrus sinensis L. Osbeck). J. Exp. Bot. 2006, 57, 633-643. [CrossRef]

42. Doğramac1, M.; Foley, M.E.; Chao, W.S.; Christoffers, M.J.; Anderson, J.V.; Dogramaci, M. Induction of endodormancy in crown buds of leafy spurge (Euphorbia esula L.) implicates a role for ethylene and cross-talk between photoperiod and temperature. Plant Mol. Biol. 2013, 81, 577-593. [CrossRef]

43. Shefferson, R.P. The evolutionary ecology of vegetative dormancy in mature herbaceous perennial plants. J. Ecol. 2009, 97, 1000-1009. [CrossRef]

44. Saniewski, M.; Ueda, J.; Miyamoto, K.; Horbowicz, M.; Puchalski, J. Hormonal control of gummosis in Rosaceae. J. Fruit Ornam. Plant Res. 2006, 14, 137-143.

45. Li, Z.; Zhu, W.; Fan, Y.-C.; Ye, J.-L.; Li, G.-H. Effects of pre- and post-treatment with ethephon on gum formation of peach gummosis caused by Lasiodiplodia theobromae. Plant Pathol. 2014, 63, 1306-1315. [CrossRef]

46. Skirycz, A.; Claeys, H.; De Bodt, S.; Oikawa, A.; Shinoda, S.; Andriankaja, M.; Maleux, K.; Eloy, N.; Coppens, F.; Yoo, S.-D.; et al. Pause-and-Stop: The Effects of Osmotic Stress on Cell Proliferation during Early Leaf Development in Arabidopsis and a Role for Ethylene Signaling in Cell Cycle Arrest. Plant Cell 2011, 23, 1876-1888. [CrossRef] [PubMed]

47. Kalcsits, L.A.; Silim, S.; Tanino, K. Warm temperature accelerates short photoperiod-induced growth cessation and dormancy induction in hybrid poplar (Populus $\times$ spp.). Trees 2009, 23, 971-979. [CrossRef]

48. Kalberer, S.R.; Wisniewski, M.; Arora, R. Deacclimation and reacclimation of cold-hardy plants: Current understanding and emerging concepts. Plant Sci. 2006, 171, 3-16. [CrossRef]

49. Shin, H.; Oh, S.-I.; Kim, M.-A.; Yun, S.K.; Oh, Y.; Son, I.-C.; Kim, H.-S.; Kim, D. Relationship between cold hardiness and dehydrin gene expression in peach shoot tissues under field conditions. Hortic. Environ. Biotechnol. 2015, 56, 280-287. [CrossRef]

50. Rubio, S.; Dantas, D.; Bressan-Smith, R.; Pérez, F.J. Relationship Between Endodormancy and Cold Hardiness in Grapevine Buds. J. Plant Growth Regul. 2016, 35, 266-275. [CrossRef]

51. Duan, X.; Cai, C.; Yang, Y.; Chen, F.; Sang, Z.; Ma, L. Fall Ethephon Application Enhances the Freezing Tolerance of Magnolia wufengensis During Overwintering. Forests 2019, 10, 868. [CrossRef]

52. Durner, E.F. Cryoprotection of deacclimating peach flower buds by ethephon alteration of pistil carbohydrate content. Cryobiology 1989, 26, 290-296. [CrossRef]

53. Ciardi, J.A.; Deikman, J.; Orzolek, M.D. Increased ethylene synthesis enhances chilling tolerance in tomato. Physiol. Plant. 1997, 101, 333-340. [CrossRef]

54. Tian, Y.; Zhang, H.; Pan, X.; Chen, X.; Zhang, Z.; Lu, X.; Huang, R. Overexpression of ethylene response factor TERF2 confers cold tolerance in rice seedlings. Transgenic Res. 2011, 20, 857-866. [CrossRef] [PubMed]

55. Zhang, Z.; Huang, R. Enhanced tolerance to freezing in tobacco and tomato overexpressing transcription factor TERF2/LeERF2 is modulated by ethylene biosynthesis. Plant Mol. Biol. 2010, 73, 241-249. [CrossRef] [PubMed]

56. Hayat, S.; Hayat, Q.; Alyemeni, M.N.; Wani, A.S.; Pichtel, J.; Ahmad, A. Role of proline under changing environments. Plant Signal. Behav. 2012, 7, 1456-1466. [CrossRef] [PubMed]

57. Gavelienè, V.; Pakalniškytė, L.; Novickienè, L. Regulation of proline and ethylene levels in rape seedlings for freezing tolerance. Open Life Sci. 2014, 9, 1099-1107. [CrossRef]

58. Turnbull, C.G.N.; Sinclair, E.R.; Anderson, K.L.; Nissen, R.J.; Shorter, A.J.; Lanham, T.E. Routes of Ethephon Uptake in Pineapple (Ananas comosus) and Reasons for Failure of Flower Induction. J. Plant Growth Regul. 1999, 18, 145-152. [CrossRef]

59. Souza, F.; Alves, E.; Pio, R.; Castro, E.; Reighard, G.; Freire, A.I.; Mayer, N.A.; Pimentel, R. Influence of Temperature on the Development of Peach Fruit in a Subtropical Climate Region. Agronomy 2019, 9, 20. [CrossRef]

60. Durner, E.F.; Gianfagna, T.J.; Rooney, F.X.; Teiger, G.S.; Seiler, M.J.; Cantarella, M.J. Harvest Date and Size Distribution of Peach Fruit Are Altered with Fall-applied Ethephon. HortScience 1990, 25, 911-913. [CrossRef]

61. Zheng, C.; Halaly, T.; Acheampong, A.K.; Takebayashi, Y.; Jikumaru, Y.; Kamiya, Y.; Or, E. Abscisic acid (ABA) regulates grape bud dormancy, and dormancy release stimuli may act through modification of ABA metabolism. J. Exp. Bot. 2015, 66, 1527-1542. [CrossRef]

62. Ewang, D.; Egao, Z.; Edu, P.; Exiao, W.; Etan, Q.; Echen, X.; Eli, L.; Egao, D. Expression of ABA Metabolism-Related Genes Suggests Similarities and Differences Between Seed Dormancy and Bud Dormancy of Peach (Prunus persica). Front. Plant Sci. 2016, 6, 1248. [CrossRef]

63. Li, J.; Xu, Y.; Niu, Q.; He, L.; Teng, Y.; Bai, S. Abscisic Acid (ABA) Promotes the Induction and Maintenance of Pear (Pyrus pyrifolia White Pear Group) Flower Bud Endodormancy. Int. J. Mol. Sci. 2018, 19, 310. [CrossRef] [PubMed]

64. Eriksson, S.; Böhlenius, H.; Moritz, T.; Nilsson, O. GA4 Is the Active Gibberellin in the Regulation of LEAFY Transcription and Arabidopsis Floral Initiation. Plant Cell 2006, 18, 2172-2181. [CrossRef] [PubMed] 
65. Rinne, P.L.; Welling, A.; Vahala, J.; Ripel, L.; Ruonala, R.; Kangasjärvi, J.; van der Schoot, C. Chilling of Dormant Buds Hyperinduces FLOWERING LOCUS T and Recruits GA-Inducible 1,3- $\beta$-Glucanases to Reopen Signal Conduits and Release Dormancy in Populus. Plant Cell 2011, 23, 130-146. [CrossRef]

66. Zhuang, W.; Gao, Z.; Wang, L.; Zhong, W.; Ni, Z.; Zhang, Z. Comparative proteomic and transcriptomic approaches to address the active role of GA4 in Japanese apricot flower bud dormancy release. J. Exp. Bot. 2013, 64, 4953-4966. [CrossRef] [PubMed]

67. Zheng, C.; Acheampong, A.K.; Shi, Z.; Halaly, T.; Kamiya, Y.; Ophir, R.; Galbraith, D.W.; Or, E. Distinct gibberellin functions during and after grapevine bud dormancy release. J. Exp. Bot. 2018, 69, 1635-1648. [CrossRef] [PubMed]

68. Widemann, E.; Smirnova, E.; Aubert, Y.; Miesch, L.; Heitz, T. Dynamics of Jasmonate Metabolism upon Flowering and across Leaf Stress Responses in Arabidopsis thaliana. Plants 2016, 5, 4. [CrossRef] [PubMed]

69. Maciejewska, B.; Kopcewicz, J. Inhibitory Effect of Methyl Jasmonate on Flowering and Elongation Growth in Pharbitis nil. J. Plant Growth Regul. 2002, 21, 216-223. [CrossRef]

70. Niwa, T.; Suzuki, T.; Takebayashi, Y.; Ishiguro, R.; Higashiyama, T.; Sakakibara, H.; Ishiguro, S. Jasmonic acid facilitates flower opening and floral organ development through the upregulated expression of SIMYB21 transcription factor in tomato. Biosci. Biotechnol. Biochem. 2018, 82, 292-303. [CrossRef] [PubMed]

71. Yildiz, K.; Yazici, C.; Muradoğlu, F. Effect of jasmonic acid on germination dormant and nondormant apple seeds. Asian J. Chem. 2007, 19, 1098-1102.

72. Singh, P.; Dave, A.; Vaistij, F.E.; Worrall, D.; Holroyd, G.H.; Wells, J.G.; Kaminski, F.; Graham, I.A.; Roberts, M.R. Jasmonic acid-dependent regulation of seed dormancy following maternal herbivory in Arabidopsis. New Phytol. 2017, 214, 1702-1711. [CrossRef] [PubMed]

73. Howe, G.T.; Horvath, D.P.; Dharmawardhana, P.; Priest, H.D.; Mockler, T.C.; Strauss, S.H. Extensive Transcriptome Changes During Natural Onset and Release of Vegetative Bud Dormancy in Populus. Front. Plant Sci. 2015, 6, 989. [CrossRef]

74. Heitz, T.; Smirnova, E.; Widemann, E.; Aubert, Y.; Pinot, F.; Ménard, R. The Rise and Fall of Jasmonate Biological Activities. Prokaryotic Cytoskelet. 2016, 86, 405-426. [CrossRef]

75. Ionescu, I.A.; López-Ortega, G.; Burow, M.; Bayo-Canha, A.; Junge, A.; Gericke, O.; Møller, B.L.; Sánchez-Pérez, R. Transcriptome and Metabolite Changes during Hydrogen Cyanamide-Induced Floral Bud Break in Sweet Cherry. Front. Plant Sci. 2017, 8, 1233. [CrossRef] [PubMed]

76. E Farmer, E.; Goossens, A. Jasmonates: What ALLENE OXIDE SYNTHASE does for plants. J. Exp. Bot. 2019, 70, 3373-3378. [CrossRef]

77. Suttle, J.C. Involvement of Ethylene in Potato Microtuber Dormancy. Plant Physiol. 1998, 118, 843-848. [CrossRef] [PubMed]

78. Sumitomo, K.; Narumi, T.; Satoh, S.; Hisamatsu, T. Involvement of the ethylene response pathway in dormancy induction in chrysanthemum. J. Exp. Bot. 2008, 59, 4075-4082. [CrossRef] [PubMed]

79. Ruttink, T.; Arend, M.; Morreel, K.; Storme, V.; Rombauts, S.; Fromm, J.; Bhalerao, R.; Boerjan, W.; Rohde, A. A Molecular Timetable for Apical Bud Formation and Dormancy Induction in Poplar. Plant Cell 2007, 19, 2370-2390. [CrossRef]

80. Houben, M.; Van De Poel, B. 1-Aminocyclopropane-1-Carboxylic Acid Oxidase (ACO): The Enzyme That Makes the Plant Hormone Ethylene. Front. Plant Sci. 2019, 10, 695. [CrossRef]

81. Ophir, R.; Pang, X.; Halaly, T.; Venkateswari, J.; Lavee, S.; Galbraith, D.; Or, E. Gene-expression profiling of grape bud response to two alternative dormancy-release stimuli expose possible links between impaired mitochondrial activity, hypoxia, ethylene-ABA interplay and cell enlargement. Plant Mol. Biol. 2009, 71, 403-423. [CrossRef] [PubMed] 